\title{
الملابس وصحة الإنسان في القرن الحادي والعشرون
}

\author{
إعـــــــاد \\ ه. منالــ البكركي المتولحسـ أحمد \\ مدرس الملابس والنسيج \\ كلية التربية النوعية \\ جامعة المنصورة
}

مجلة بحوث التربية النوعية - جامعة المنصورة

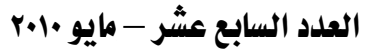




\section{الملابس وصحة الإنسان في القرن الهادي والعشرون}

$$
\text { إعـــاد }
$$

د ـ منال البكريكالمتولئحمد

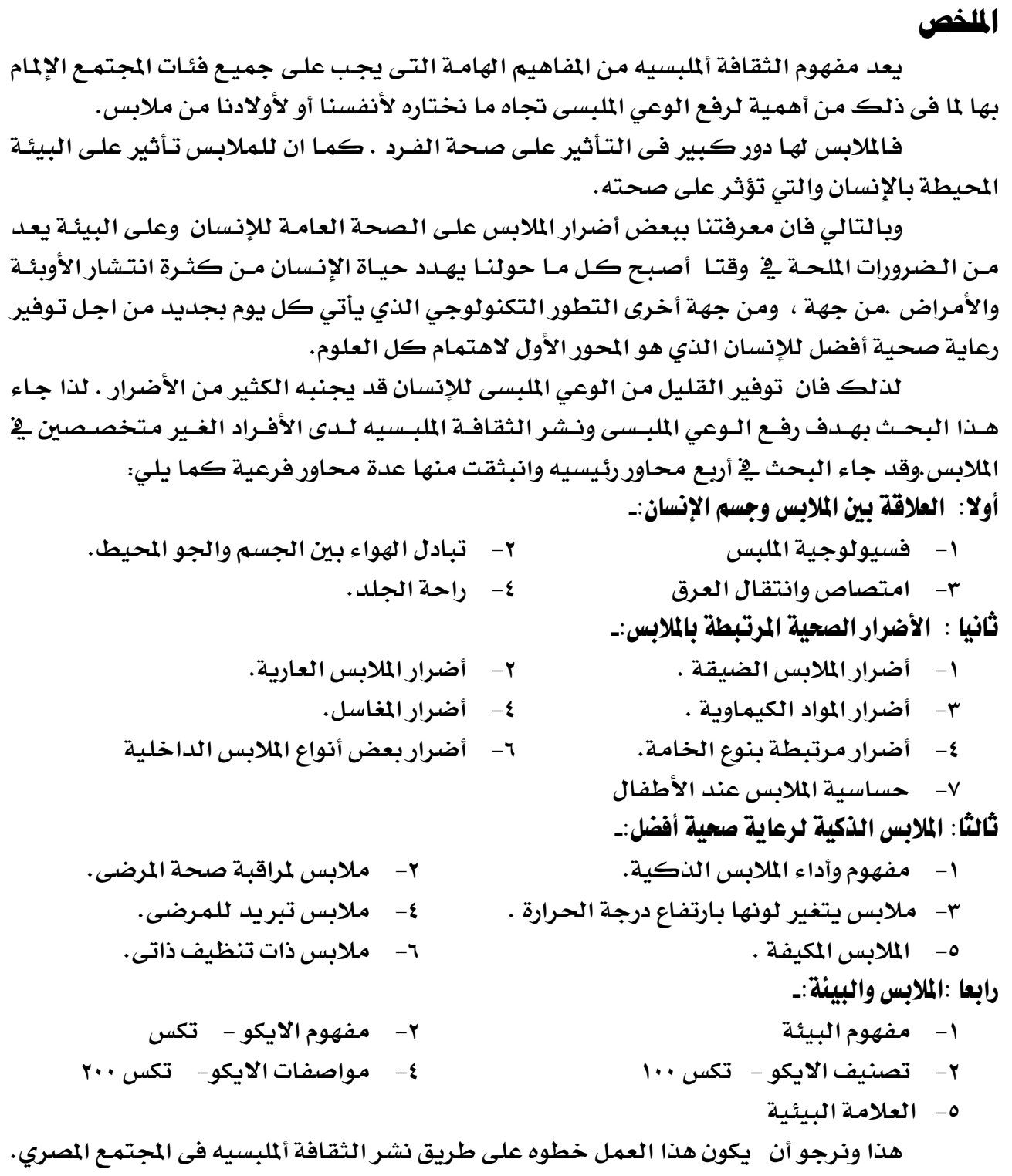




\section{الملابس وصحة الإنسان في القرن الحادي والعشرون}

$$
\text { إعــداد }
$$

دـ ـ منال البكري المتّوأحمد

\section{مقدمهه}

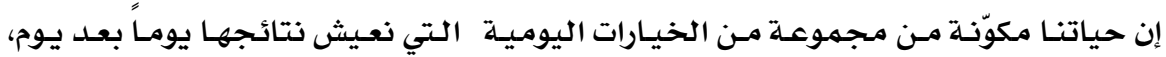

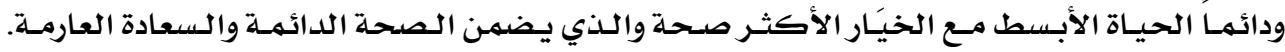

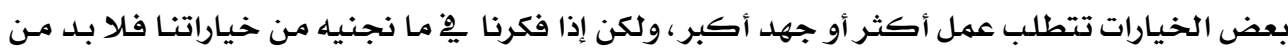

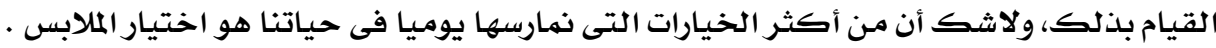

فالملابس إنها هي مـن نعهم الله علينـا، التي يجـب أن نحسن اسـتخدامها كمـا أمـرنـا رينـا عز

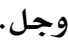

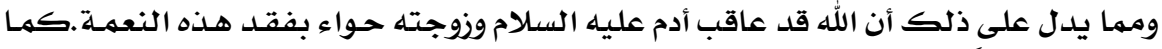

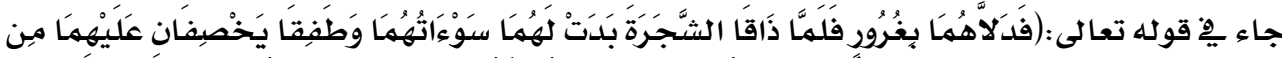

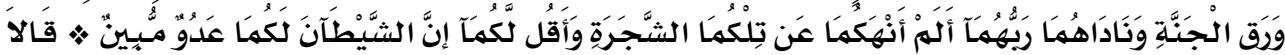

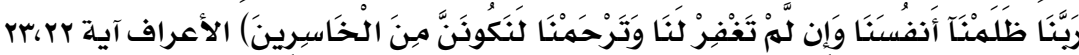
وقال مجاهد : جعلا يخصفان عليهما من ورق الجنة، قال : كهيئة الثوب (v).

وحسب تعريف منظمـة الصحة العالميـة (WHO) فـان الصحة Health هي حالـة السلامة

والكفاية البدنية والذهنية والنفسية والاجتهاعية وليست فقط مجرد الخلو من المرض أو العجز.

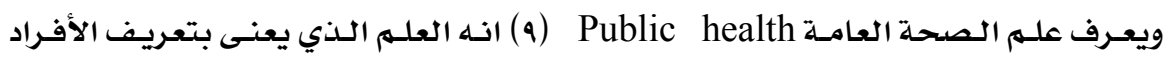

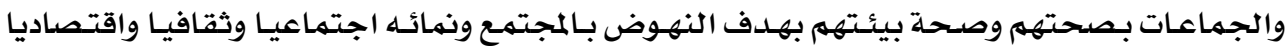
وحضاريا ورفع مستواه الصحي إلى اعلي مستوى ممكن. وللمـحافظة على هذا النمو وتقدمـه باستمـرار يجب أن يكون هنالك مشاركه ايجابيه منظمـه من مختلف الهيئات المجتهـع . وقد أكدت الكثير من الدراسـات أن هناك علاقة وثيقة بين الملابس والصحة العامة للإنسسان

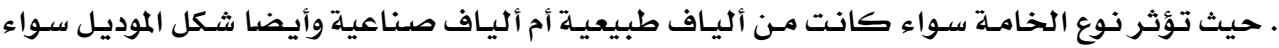

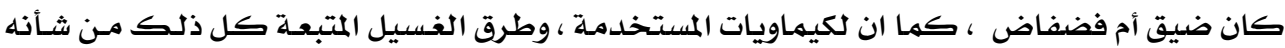

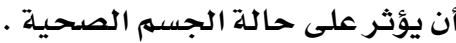
وإذا كانت البيئة هي الإطار الذي يعيث فيـه الإنسان ويحصل منـه على مقومـات حياتهـ مـن

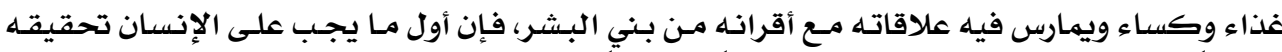

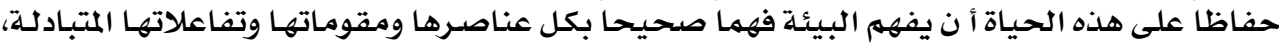


ثم أن يقوم بعمل جماعي جاد لحمايتها وتحسينها و أن يسعى للحصول على رزقه وأن يهـارس علاقاته

دون إتلاف أو إفسـاد. (10)

وفى هذا البحث سوف نحاول الوقوف على بعض الحقائق العلمية التى أكدت على العلاقة

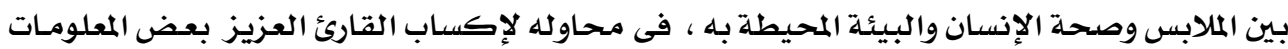

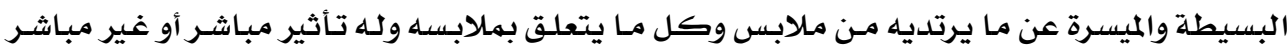

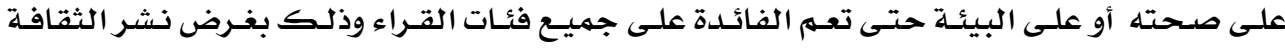

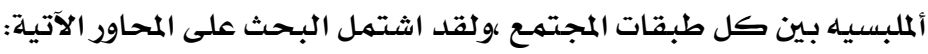
1. 1. علاقة الملابس بجسهم الإنسان.

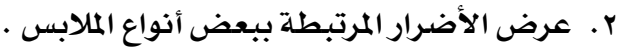

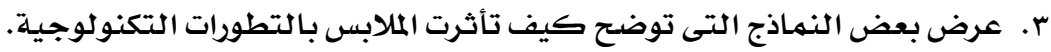
ع. توضيح علاقة الملابس بالبيئة.

تعد الملابس من نعم الله علينا ـويعتبر اختيار ما نرتديه من ملابس سلوك يومي بـل ويتكرر

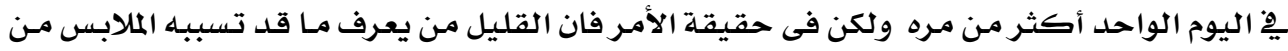

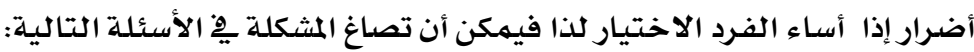
ا- ما الأضـرار الصحية الناتجة عن عدم وعى الإنسان بالأضـرار التي قد تسببها الملابس؟

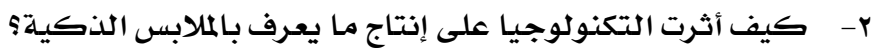

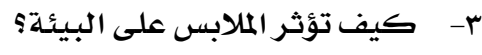

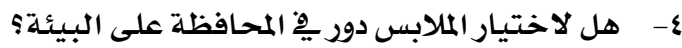

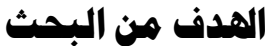

$$
\text { يهدف البـحث إلى: }
$$

ا ـ إكساب القارئ معلومات عن الأضرار المرتبطة ببعض أنواع الملابس.

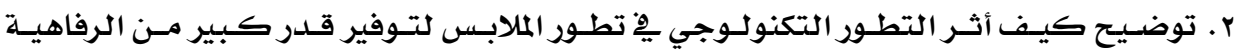

$$
\text { كلإِنسان. }
$$

r. التعرف على تأثير الملابس على البيئة .

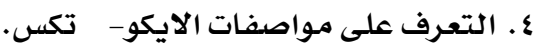

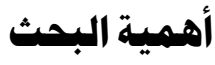

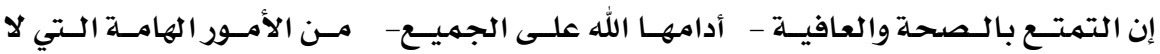

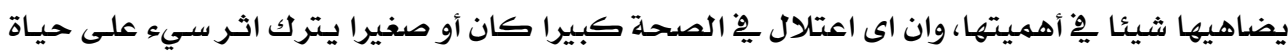

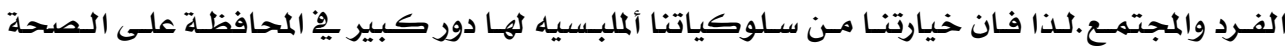
ولذ لك فان أهمية البـحث ترجـع إلى: 
1. أ. زيادة الوعي بأضرار بعض أنواع الملابس لدى غير المتخصصين.

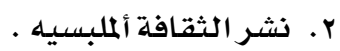

r. بالادة الوعي بأهمية البيئة والمحافظة عليها.

\section{أولا: العلاقة بين الملابس وجسم الإنسان}

\section{فسيولوجية الملبس Clothing Physiology}

\section{Heat insulation and air exchange}

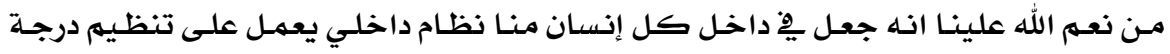

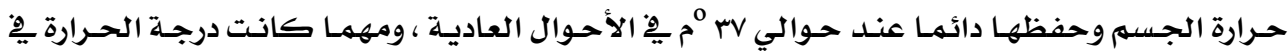

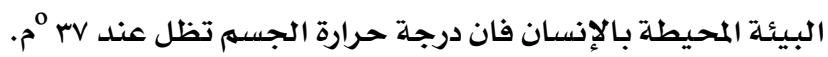

• فيولوجية الملبس في الأجواء الحارة:

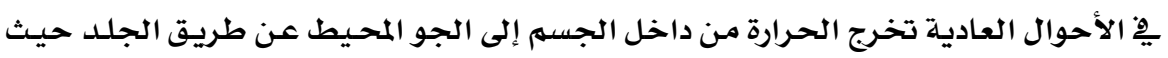

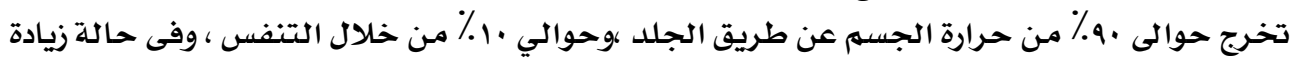

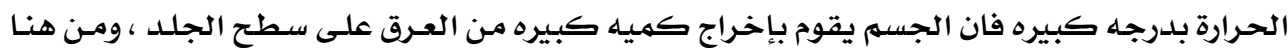

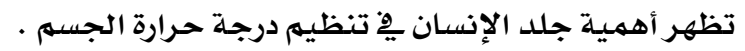

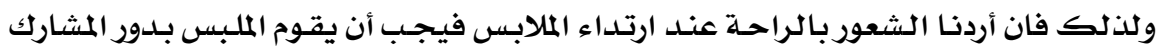

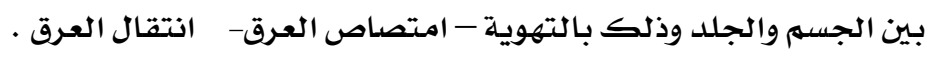

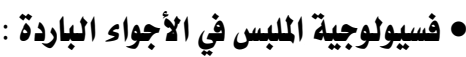

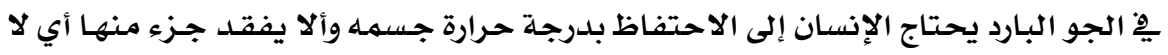

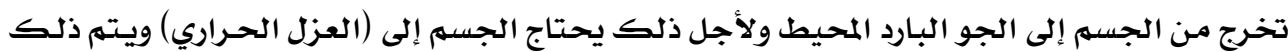

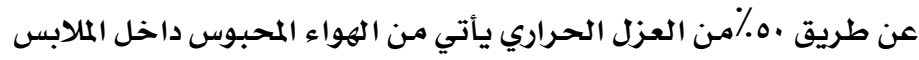

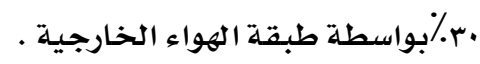

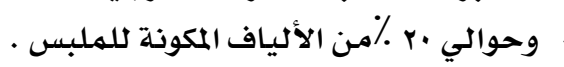

لذلك، فان الهواء المحبوس بـين الملبس و جسم الإنسان هو الأكثر تأثيرا هِّ حالـة العزل

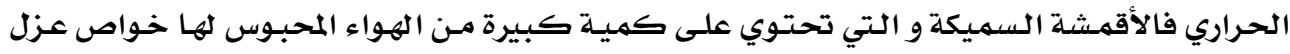

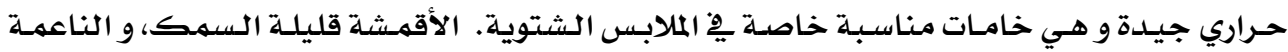

الملمس تكون أحسن هِّ الأجواء الدافئة.

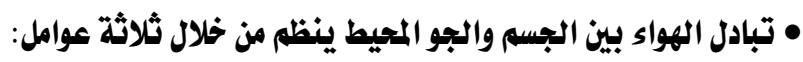

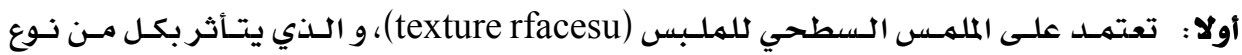

الألياف، نوع الخيوط و التركيب النسيجي، و التجهيزات التهي النهائية.

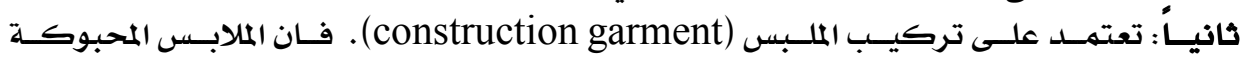

(الملاصقة للجسم) سوف تمنع التهويـة و بالتـالي تؤدي إلى عدم الراحسة لتراكم الحسرارةو 
الرطوبة. أمـا الملبوسات الفضفاضة تؤدي عادة إلى حدوث تهويـة مهـا يؤدى إلى شعور الجسهم بالراحة.

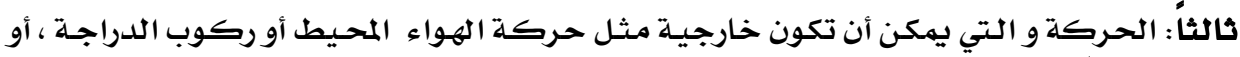

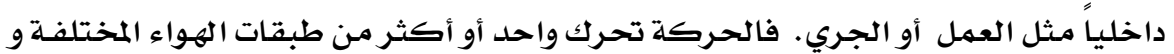

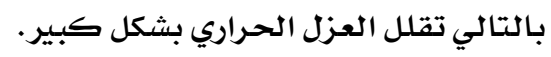

\section{• امتصاص واتتقال العرق Moisture absorption and transportation}

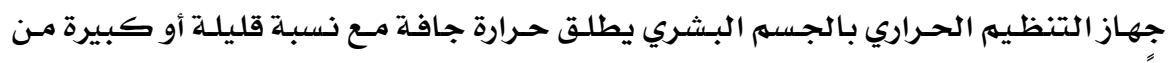

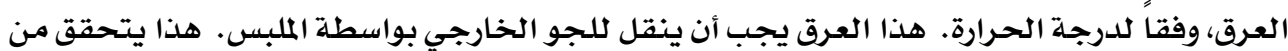

خلال:

$$
\begin{aligned}
& \text { 1- الامتصاص بداخل الألياف }
\end{aligned}
$$

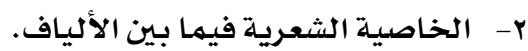

هِِ المستويات العادية من الضغط الحـراري و مستويات قليلـة إلى متوسطة مـن إخـراج العـرق

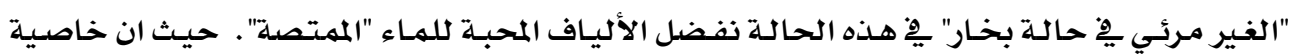

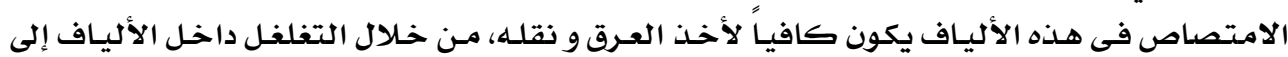

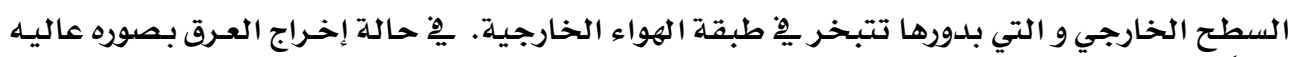

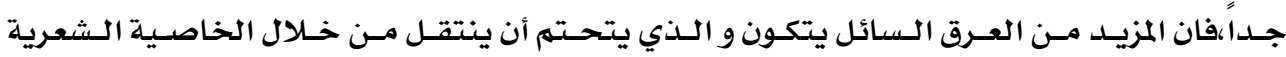
(wicking)

حيث أن الخاصية الشعرية Wicking يكون أسرع بكثير من عملية الامتصاص . لذنك فان

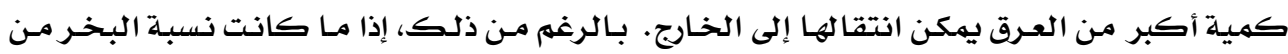

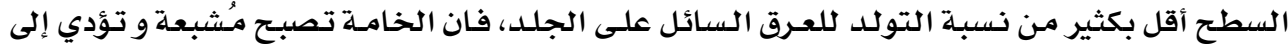

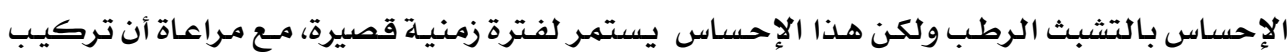

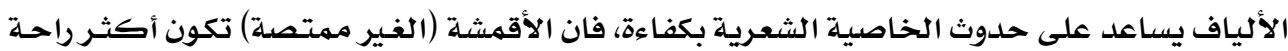
تحت بعض الظروف المناخية عن الخامات الممتصلة.

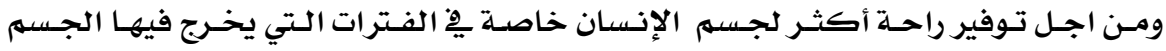

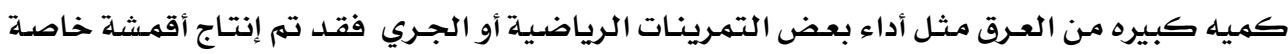
من طبقتين "ثنائية" تم تطويرها للملابس الرياضية ؛ الطبقة الداخلية من ألياف "غير ممتصدة"، مثل ميل

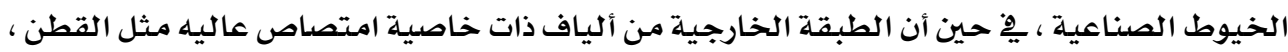

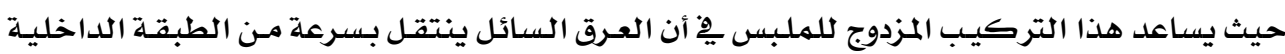

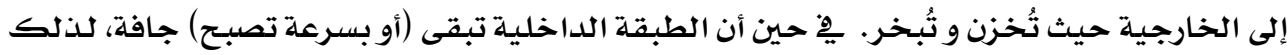

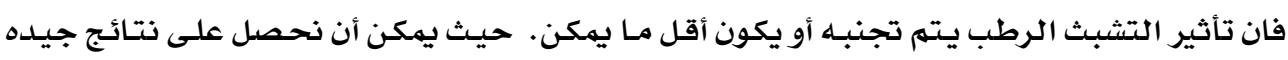

توفر راحلة أكثر للجسهم باستخدام مـيـج من الألياف ذات القدرات الامتصاصية المختلفة ( ) . 
الراحة هي عدم الشعور بالألم عند ارتداء الملابس ، كما أنها الشعور بعدم الضيق (r) (r)

الراحة الشعورية

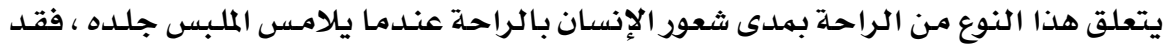

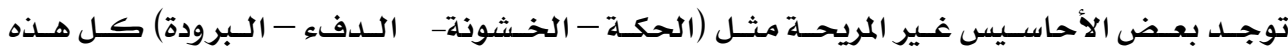

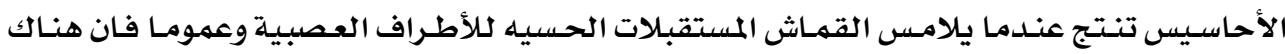

ثلاث مجموعات من العصب الحسي هي:

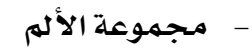

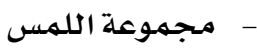

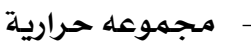

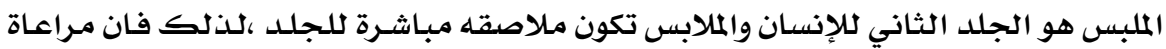

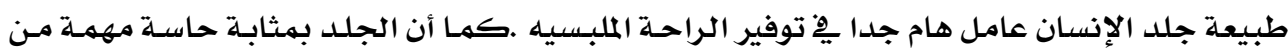

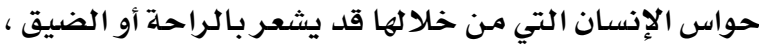

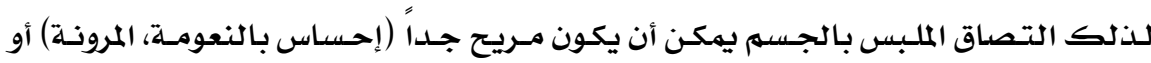

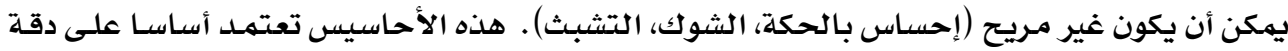

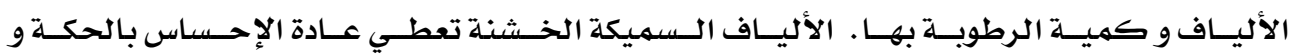
التشويك.أما الألياف الرقيقة الناعمة تعطى إحساس بالراحة الملبسية.

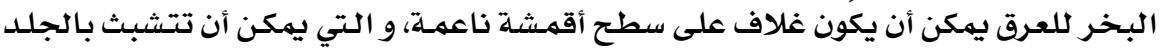

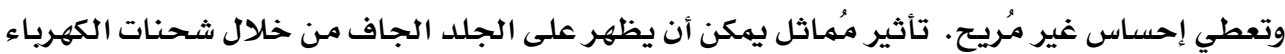

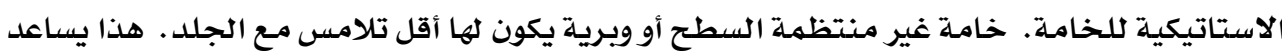

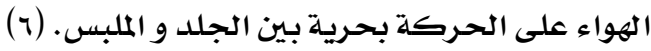
ثانيا:الأضرار الصحية لبهض أحرية أنواع الملابس

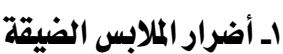

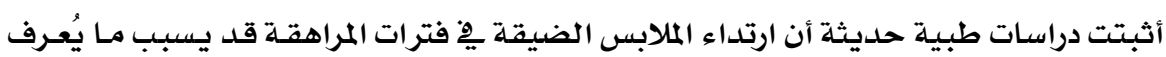

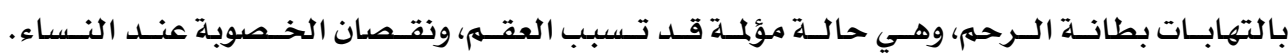

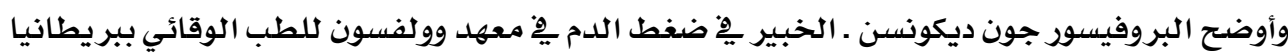

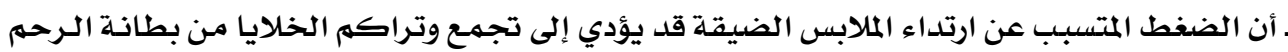
مِّ منطقة أخرى يِّ الجسم مسبباً الالتهاب.

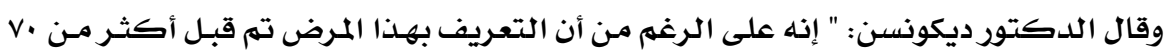

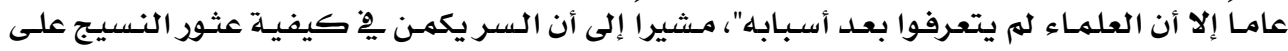


طريقه من الرحهم إلى أجزاء أخرى مـن الجسهم مثل المبايض، حيث يتجمع ويتراكم مسببـاً آلامـاً حـادة فى فترة ما قبل الطمث، وأحيانا العقمر.

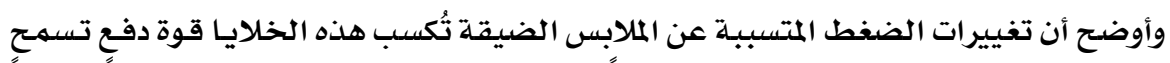

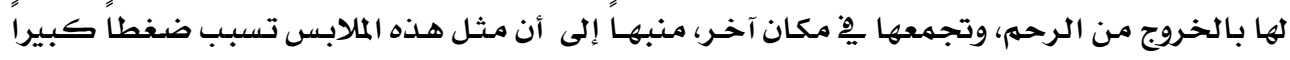

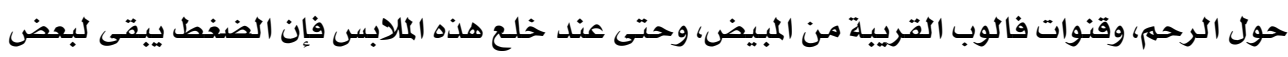

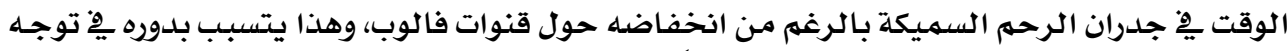

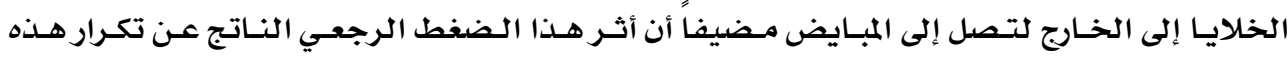

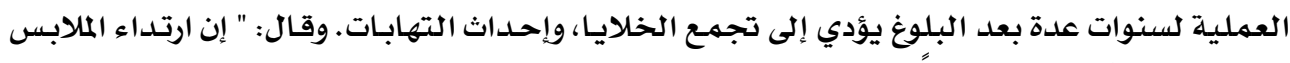

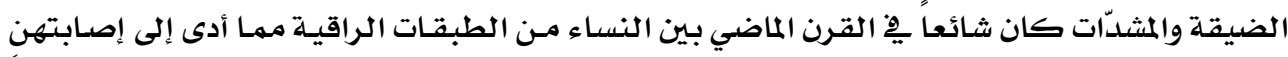

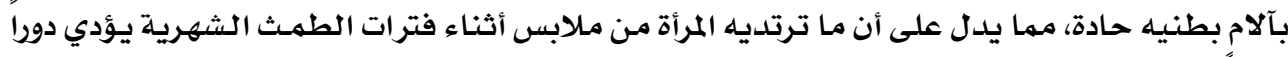

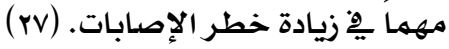

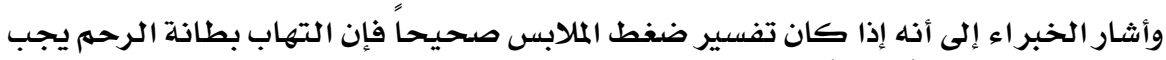

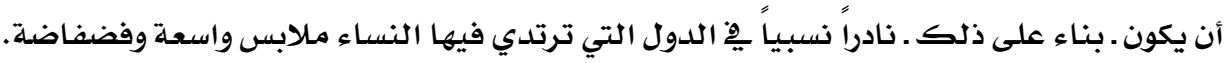

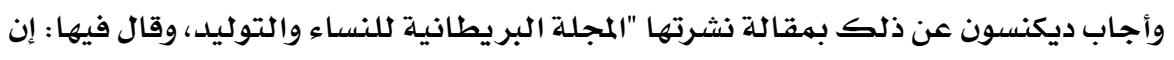

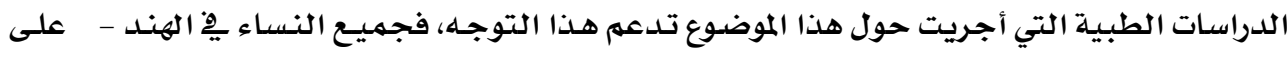

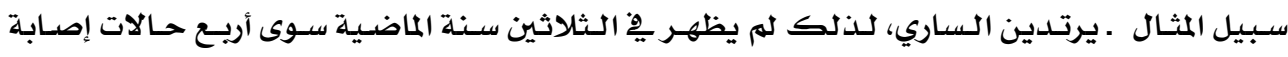

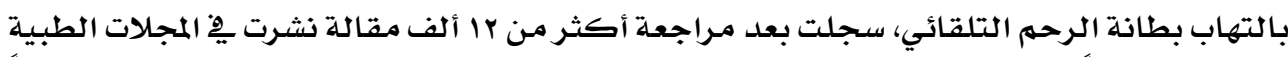

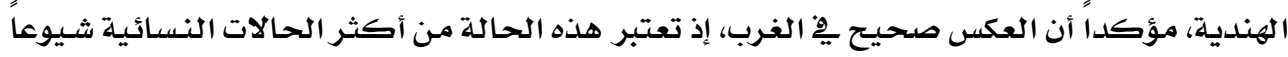

مِِّ الدول الغربية، حيث ترتدي النساء موديلات مختلفة من الملابس الضيقة.

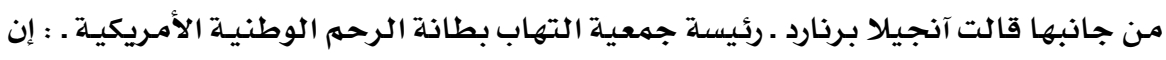

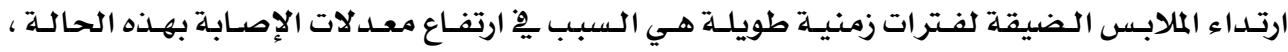
مؤكدة على أن السيدات والفتيات ضرورة تجنب ارتداء هذه الملابس، وخاصدة يِّ أثناء الدورة الشهريـة. وأكد أساتذة الصحة العامـة أن اللباس الضيق تعذيب لحرية الجسلد، وضرر صـحي لأنسجة

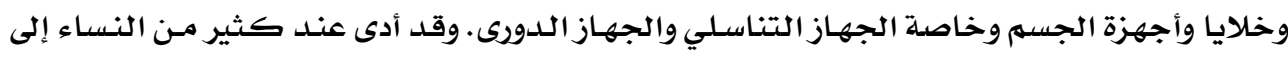

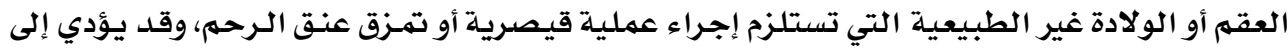
ارتفاع ضغط الدم. وهناك الكثير مـن الأمـور المتعلقـة بآثار الملابس الضيقة الضـاغطة على الجسمه، فهي تعيق الدورة الدموية وتعد من العوامل التي تزيد مشاكل حرقة من المعلدة.

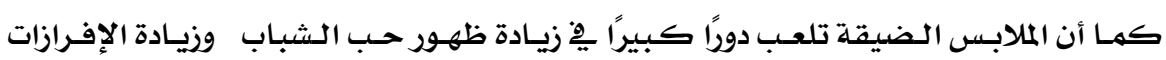

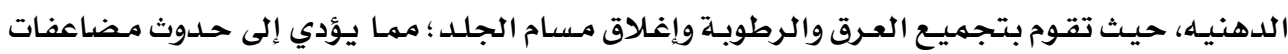

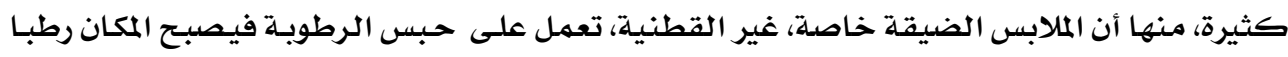

وبيئة مناسبـة لحياة الفطريات ونهوها. 
كما أن الملابس الضيقة، خاصدة الجينز، تقوم بالضغط على العصب الحسب الموجـود تحت

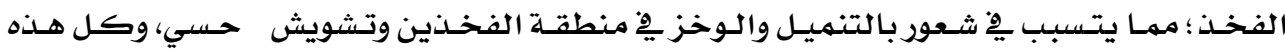

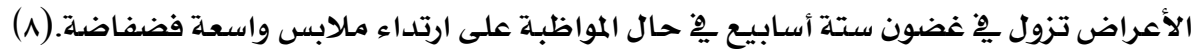

rـ أضرار الملابس العارية

أمـا الملابس العاريـة ففيهـا مـن الأضـرار الكثير، منهـا أن التعـرض لأثـعة الشمس بشكل دائم

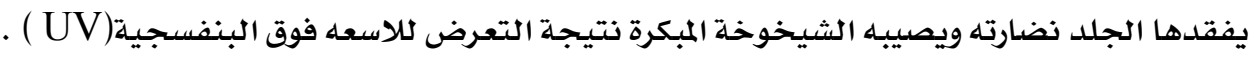

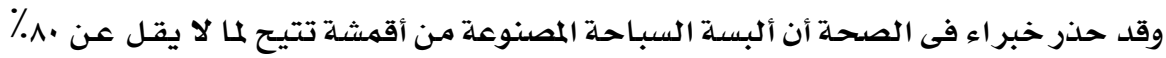
من أشعـة الشمس النفاذ منها، قد تسبب سرطان الجلد.

وأشار البـاحثون إلى أن وجود آلاف الثقوب الصغيرة جداً يِّ هـذه الألبسـة التي لا ترى بـالعين المجردة، لكن خطرها كبير جدا على الجلد.

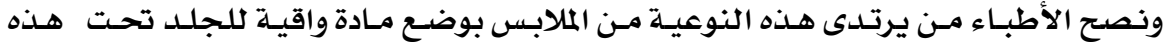

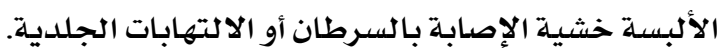

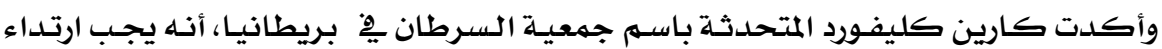

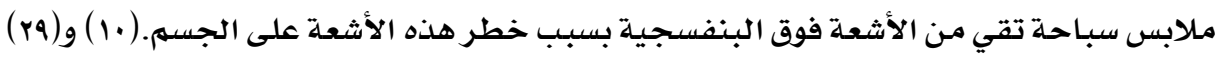

rـ أضرار المواد الكيماوية

أثبتـت دراسـات حلديثـة أن الملابس قد تكون سببـا للعديـد مـن الأمـراض التي تـتراوح بـين آلام

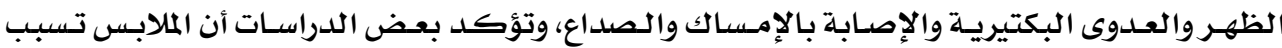

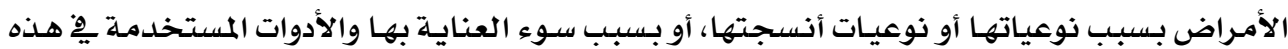

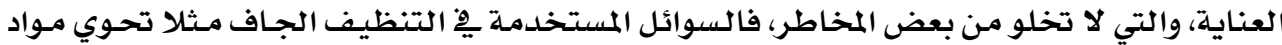

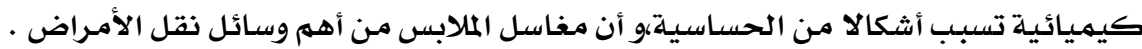

كما أن أمـراضـا جلدية ناتجـة عن ميكروبات وطفيليات تظهر ِِّ الجلد على صدورة بقع إمـا

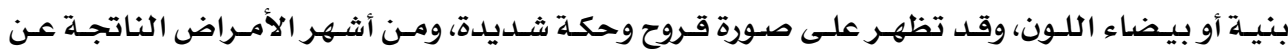
الفطريات التينيا الملونة، وأخطر الطفيليات التي تنتقل عن طريق الملابس مـن شـخص لآخـر القهـل،

عدا الأمراض الجرثومية التي تنتقل مـع الرذاذ الذي قد يختلط بالملابس مثل السل والفطريات. و أمـا عن الأمراض الجلدية الناتجة عن المواد الكيميائية المستخلدمة مـع الغسيل، ويقصد بها

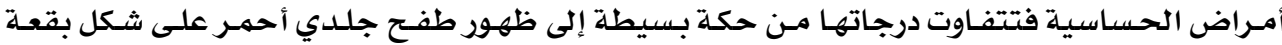

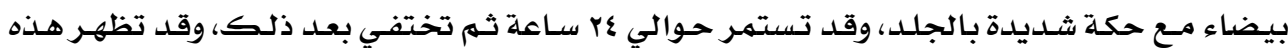

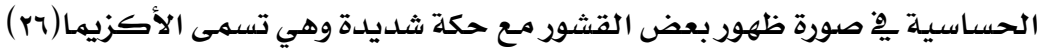
الحذزر من استخدام المنظفات والمبيضات

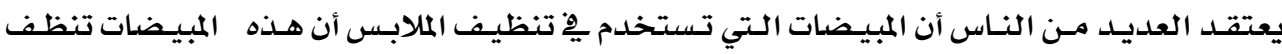

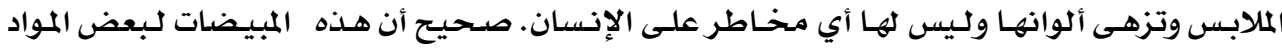


الكيميائية التي تسـاهم مِِ القضاء على البكتريا إلا أنه ِِِ الحقيقة فإن لاستخدام هـذه المبيضات آثاراً

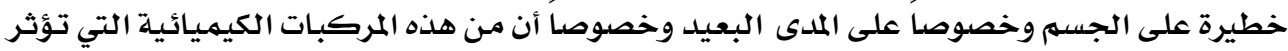
على الجسهم وتسبب له بعض الجم المشاكل هو (الكلور) مـن هـذه الخطورة ولسلامـة الإنسان وصسحته منعـت منظمـة الصحة العالميـة (who) والتي

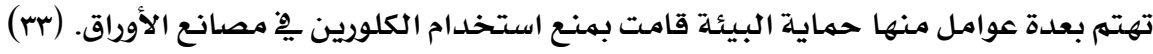
كما أن الدراسـات ِِِ هذه المجال أوضح أن المشاكل الناتجة عن الكلورين تفوق ........ مـرة

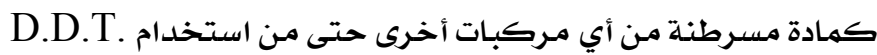
ما هو الكلورين :

(كلورين) لا يتواجد بشكل مباشر ولكن غاز أصفر نادر التواجد، ولكنه يمكن تصنيعـه بطرق

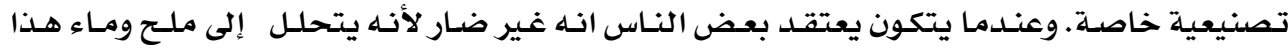

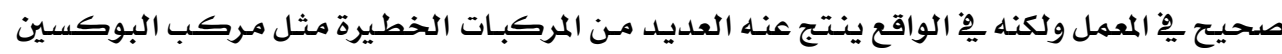

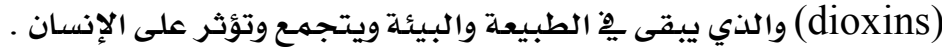

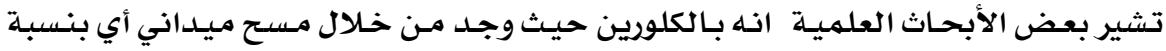

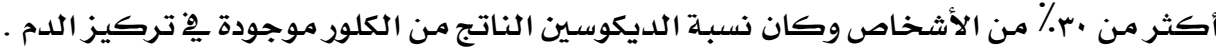
مشاكل التلوث بانكلور :

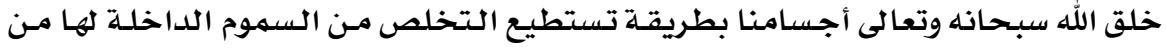

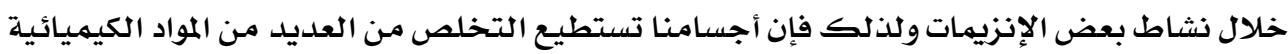

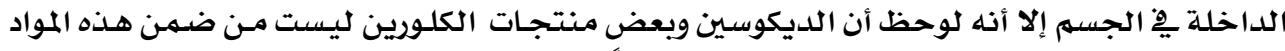

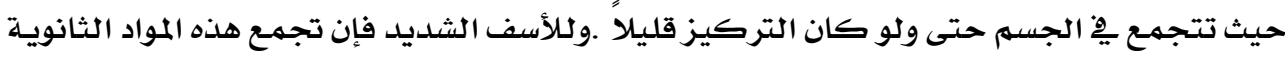

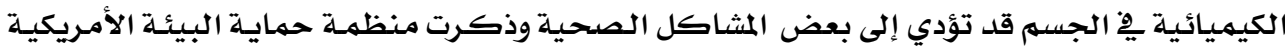

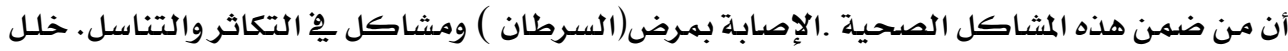

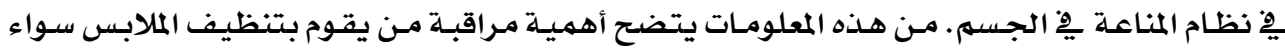

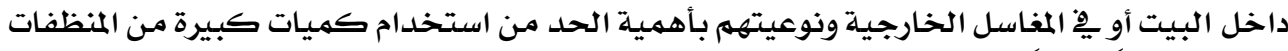

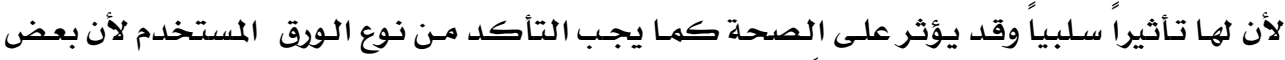

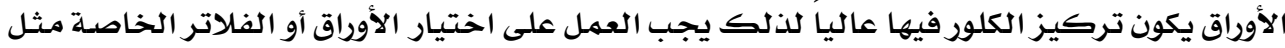

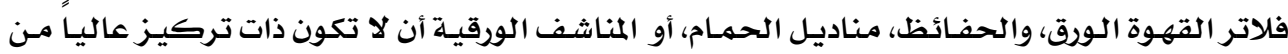

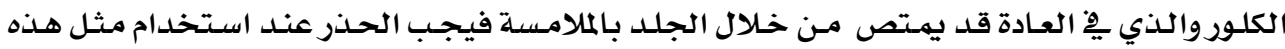

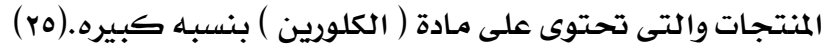

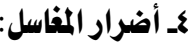

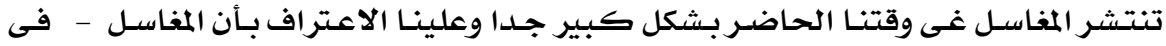

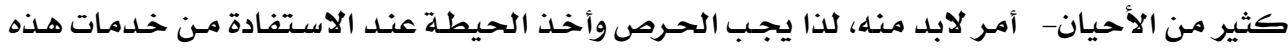




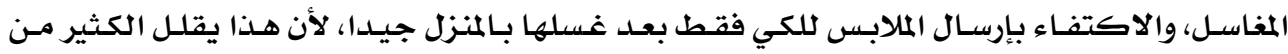

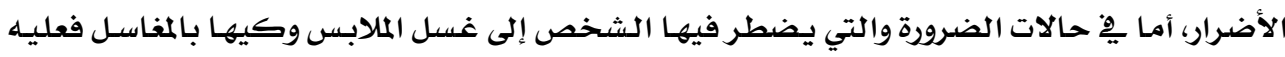

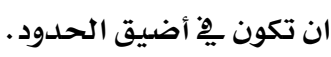

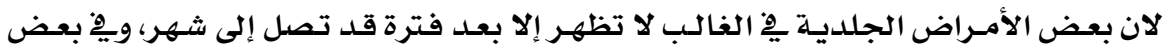

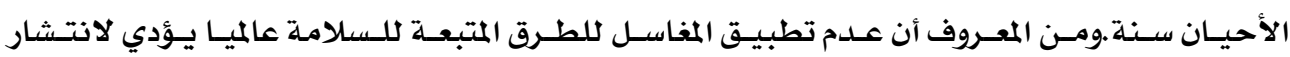

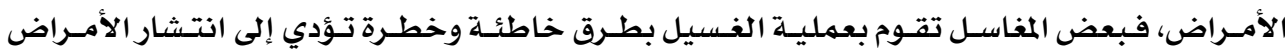

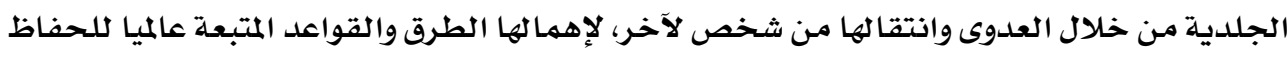

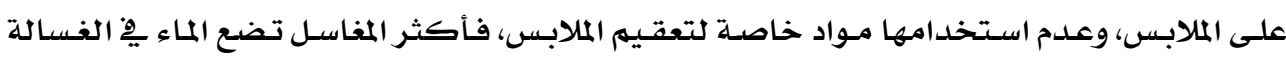

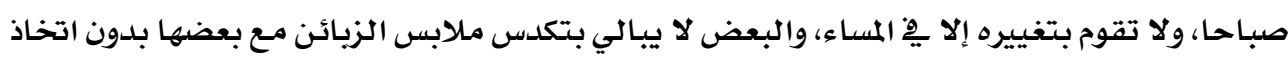

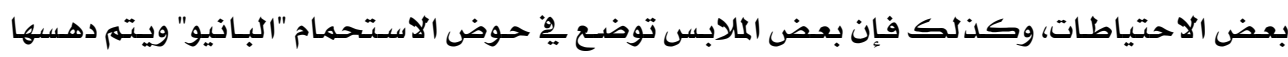

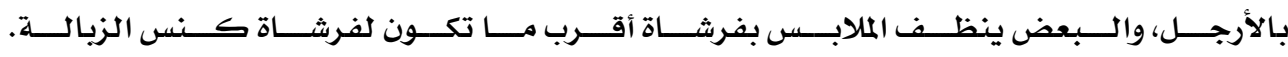

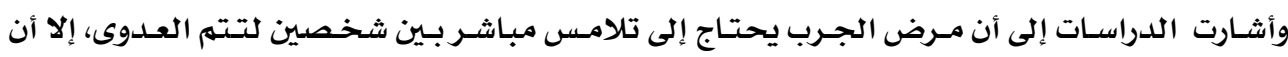

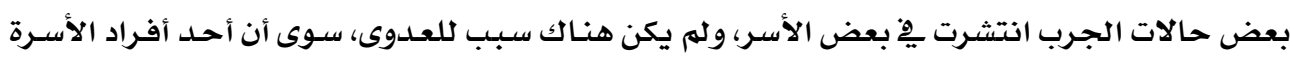

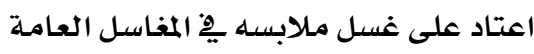

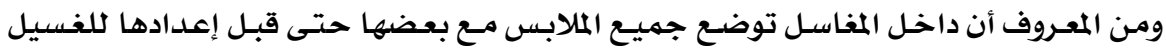

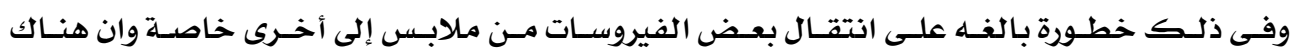

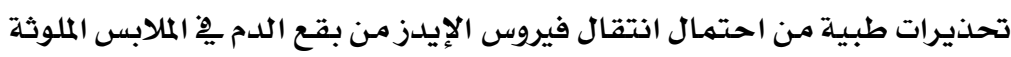

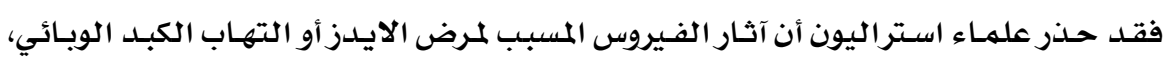

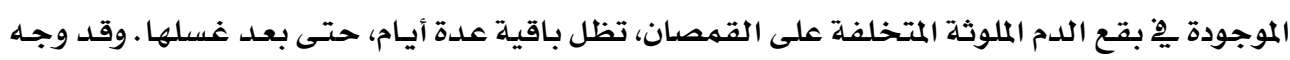

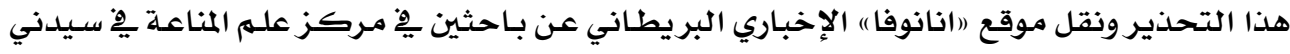

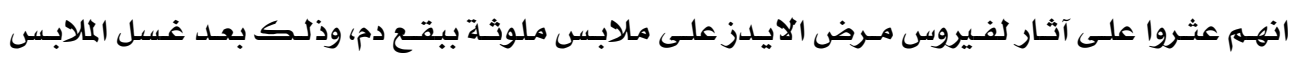

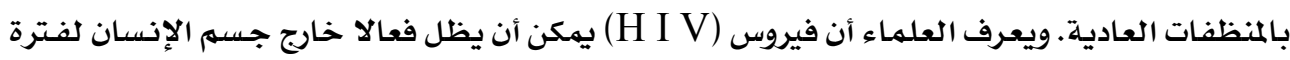

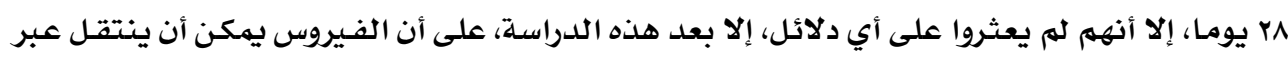

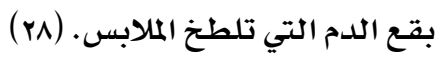

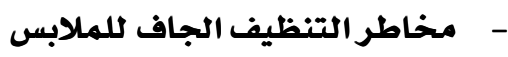

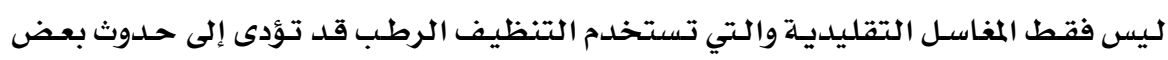

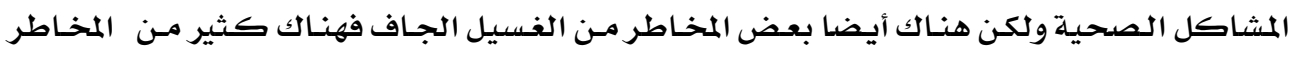

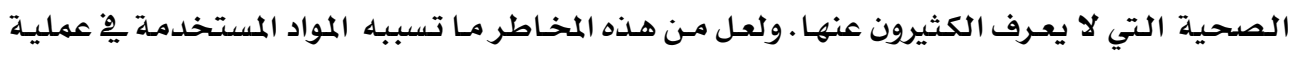

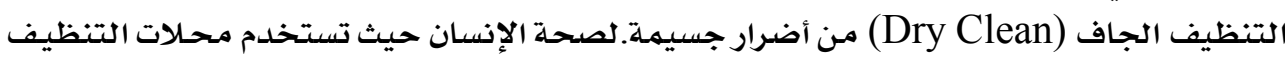

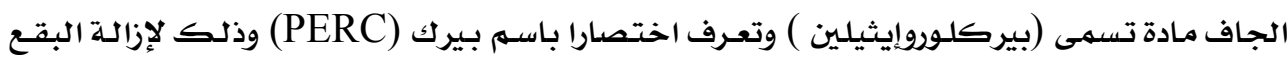

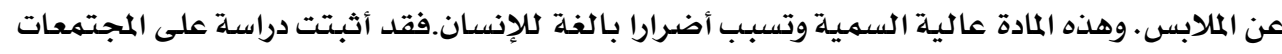

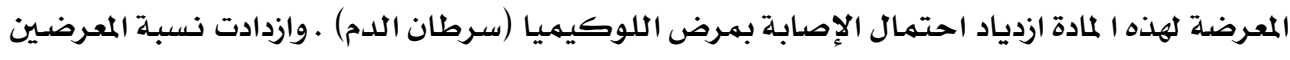




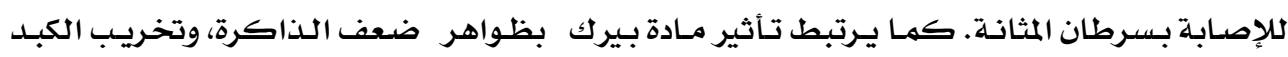

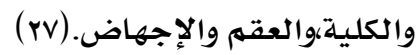

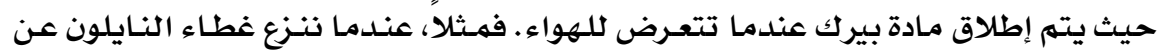

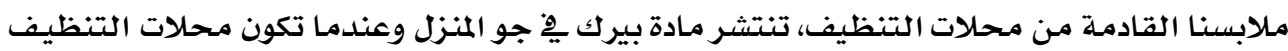

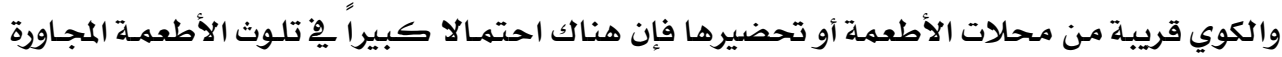
بالمادة.

ولذلك علينا اخذذ بعض الاحتياطـات لحمايـة أنفسنـا مـن هـذه المادة ومـن هـذه الاحتياطـات

تجنب تنظيف ملابسك ت تنظيفـا جافـا قدر الإمكان، وهنـاك طرق أخـرى كثيرة للتنظيف

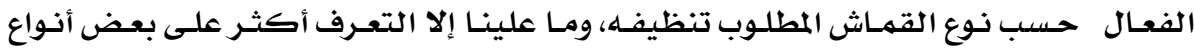

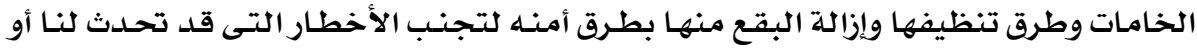

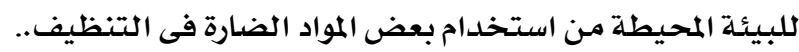

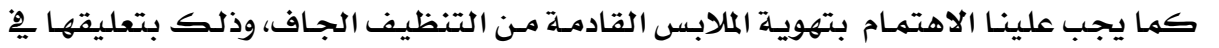

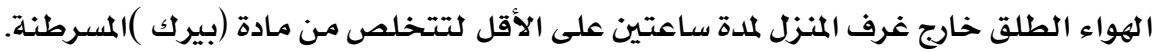

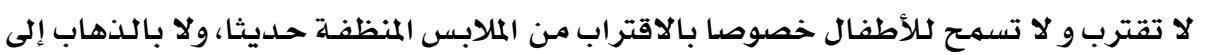

محلات التنظيف الجاف إن لهم تكن تلك المحلات ملتزمـة بإجراءات الصحسة والسلامـة. (rV)

هـ أضرار مرتبطة بنوع الخامة

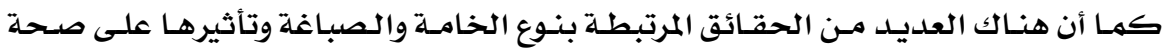
الإنسان ومنها:

- معظمى الملابس المـصنعـة مـن أليـاف صـناعية أظهـرت مقـدرة كبيره على الاحتفـاظ بالبكتريـا

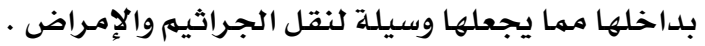

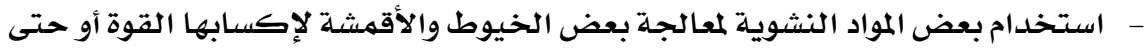

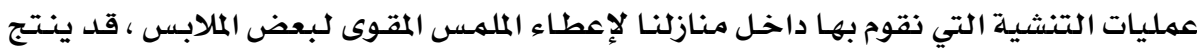

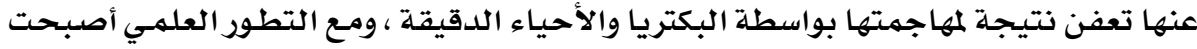

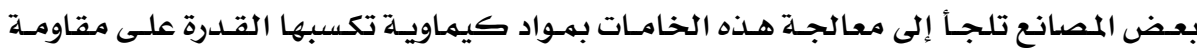

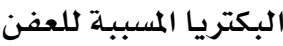
هناك العديد من الأمراض التي تصيب الفرد ناتجـة عن ( بكتريـا - فطريـات - فيروسـات) التي

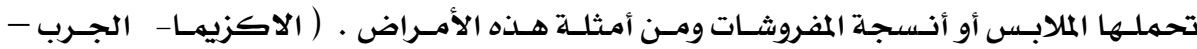

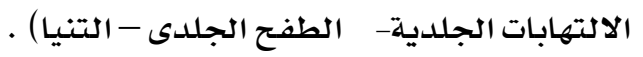

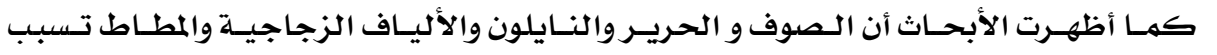

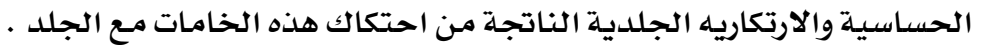


- - بعض أنواع الخامـات المصبوغة مـن الصبغات الضـارة تـترك أثرا مـن هـذه الصبغات على الجلد

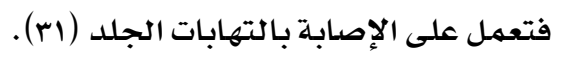

1ـ أضرار ناتجة عن ارتداء بعض الملابس الداخلية

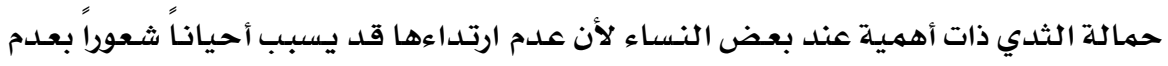

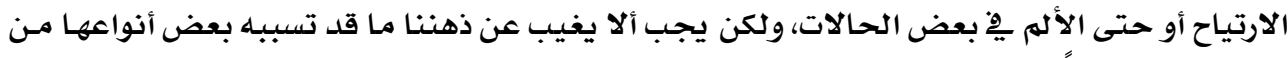

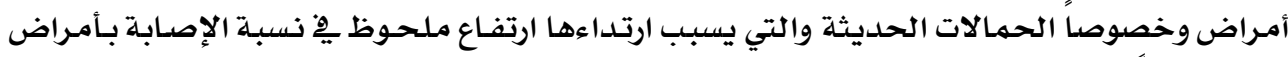

خطيرة جدا.

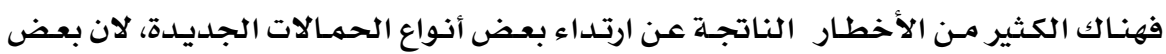

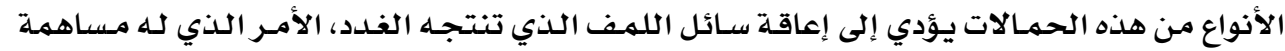

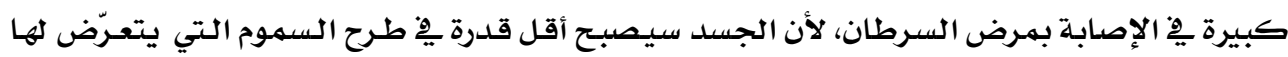

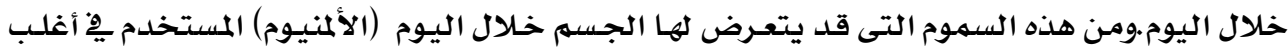

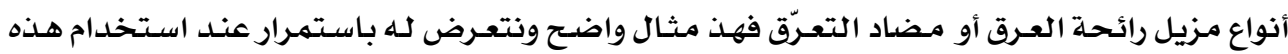

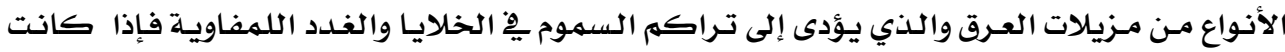

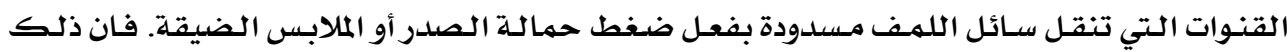

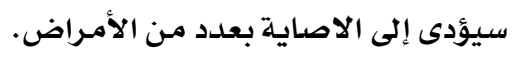

يشير الطبيـب (Michael Schacter) مِفِ كتابـاتـه عن الإجـراءات الوقائيـة للحمايـة مـن

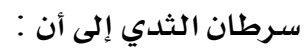

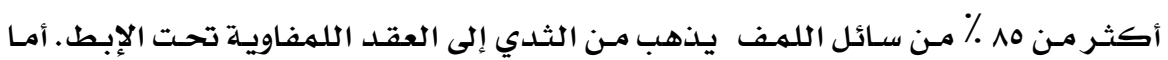

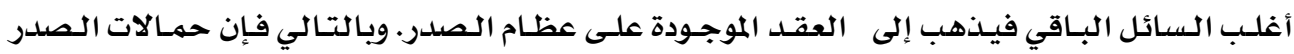

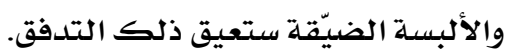

إن آليـة عمل الحمالـة التي تسبب الضيق بالإضـافة إلى زمـن ارتـاءها سـيؤثران على درجـة

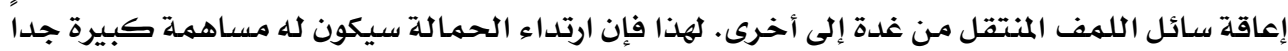

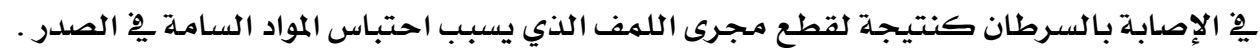
هذا وقد أثبت الطبيب (George Goodheart) مـ خـلال تجاريسه بـأن وضـع كـرة صغيرة

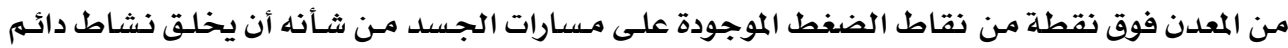

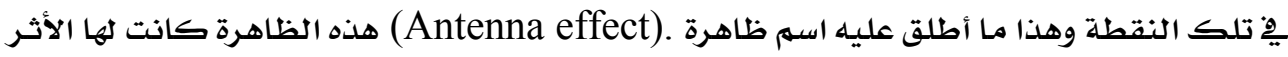

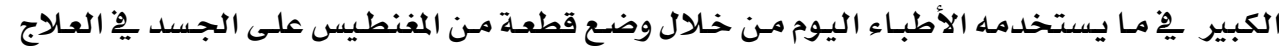
الفيزيائي.

لذلك فإن أي معدن يوضع على الجسد لفترة معينـة وفوق نقـاط معينـة مـن شـأنه أن يخلق

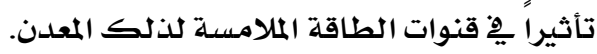




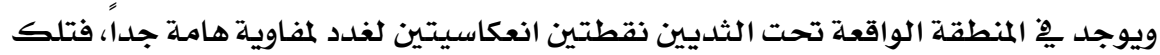
الموجودة تحت الثدي الأيهـن مـرتبطة مـع الكبد والمرارة، أمـا الموجـودة تحست الثـدي الأيسـر فهي مرتبطـة مـع المعدة.

هذه النقط الانعكاسية مثلها مثل جميع النقط الأخرى تخضع لقانون التحفيز المعروف يف

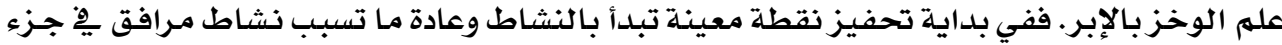

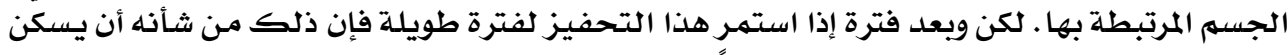

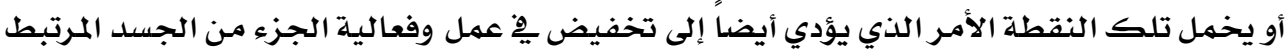

بتلك النقطة.

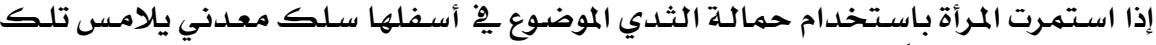

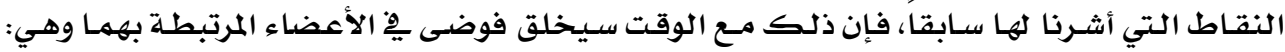
الكبد والمرارة والمعدة.وباختصار إن ذلك سيؤدي إلى جعل المرأة تمرض، بلدون حتى أن تشعر بذلك.

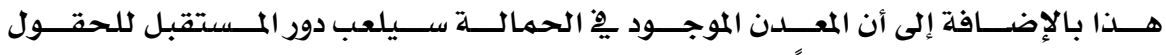

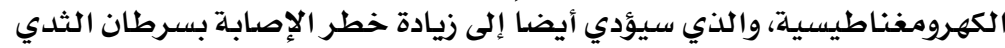

لقد أكدت بعض الدراسـات أن النسـاء اللـواتي اعتـدن على ارتـاء حمالـة الثدي يـواجهن

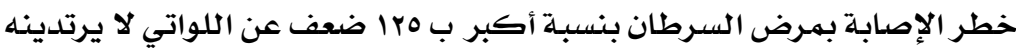

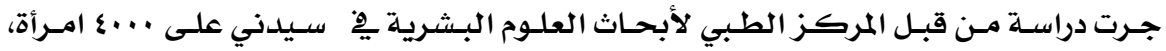

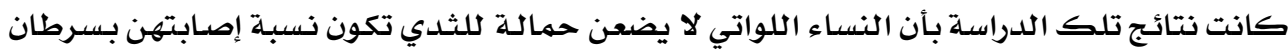

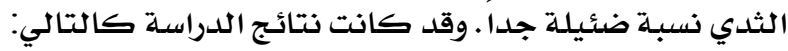
• النساء اللواتي يستخدمن الحمالة لمدة §Y سـاعة يِّا اليوم تكون نسبة الإصـابة بسرطان الثدي هي r من أصل؛.

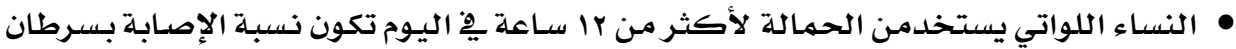

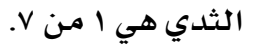

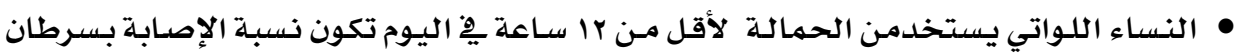

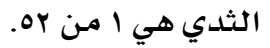

• النساء اللواتي يستخدمن الحمالـة نادرا أو لا يستخدمنها أبـاً تكون نسبـة الإصـابة بسرطان

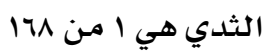

بالاعتمـاد على نتائج هذه الدراسـة فإن النسـاء اللـواتي يرتــين حمالـة الثدي يكن معرضـات

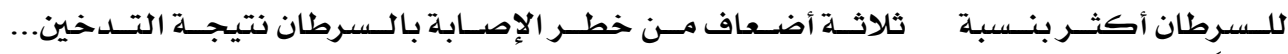

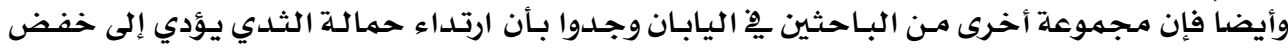

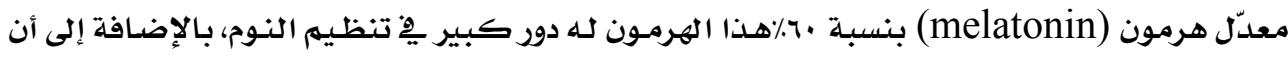




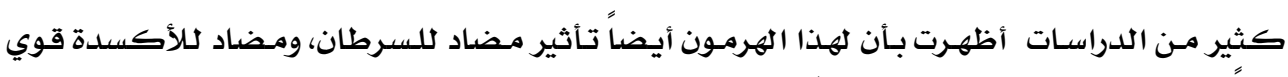

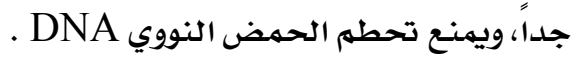
ارتداء المعدن على الجسد هو شيء يجب تجنبه مهما كانت الأسباب.

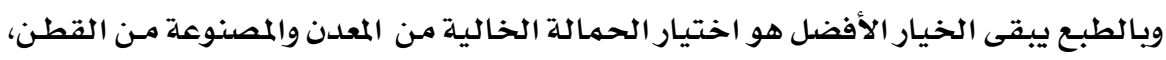
وأيضاً يمكن اختيار الحمالات الخاصة بالريار الاضياضة...

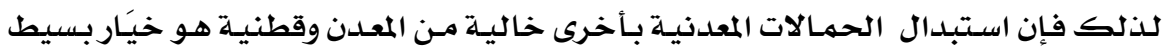
وخالي من التعقيد بهدف الحصول على صحة ممتازة وجسد سليه.

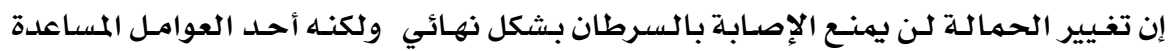

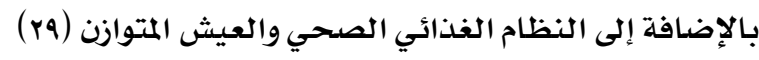

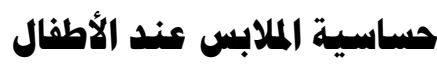

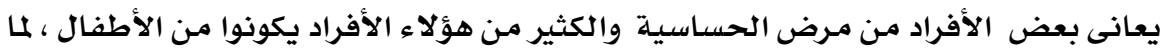

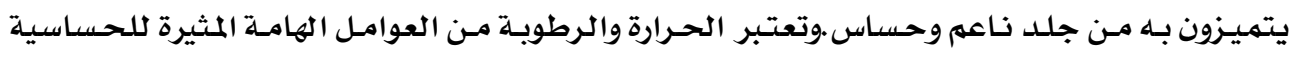

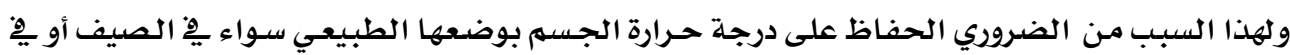

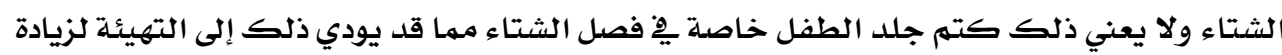

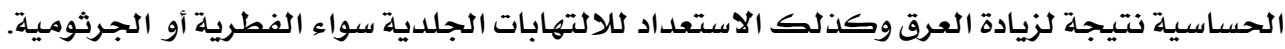

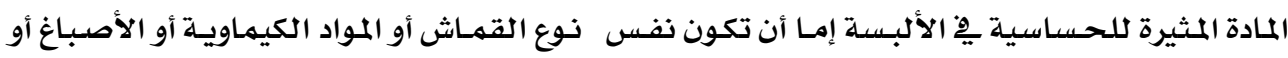

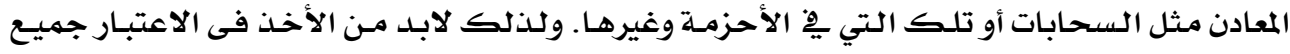

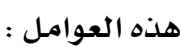

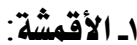

\section{• القطن: عادة لا يثير الحساسية وهو أقل أنواع الأقمشة المسببـة للحساسية.}

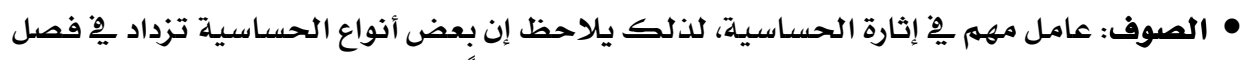

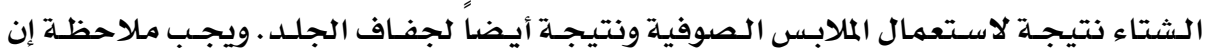

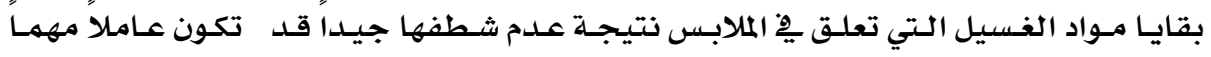

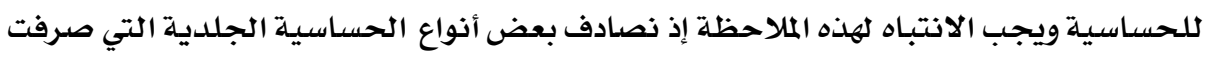

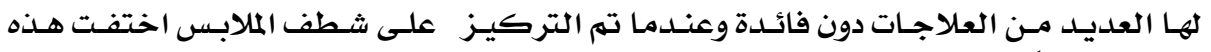

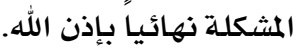

$$
\text { • الحرير: نادراً ما يؤدي إلى الحساسية. }
$$

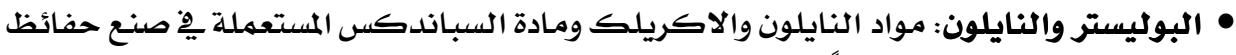

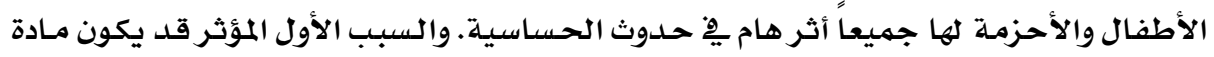

$$
\text { القماش أو الأصباغ. }
$$


• مـادة السباندكس: هذه مـاده غير مطاطيـة قابله للشد مـن البوليوريثين تستعمل ِِّ صـناعة

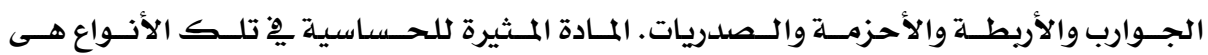
(ميركابتوبنزوثايزول.)

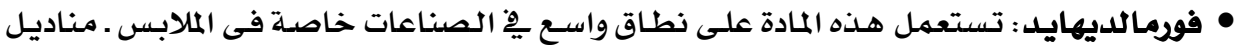

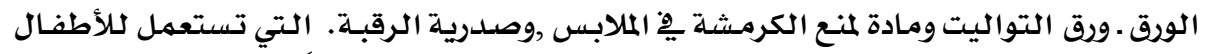

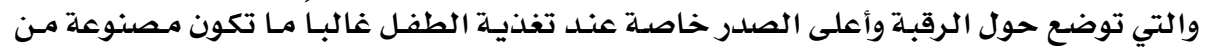
مواد مثيرة للحساسية لذلك من الضروري اختيار نوع قطني غير مؤثر.

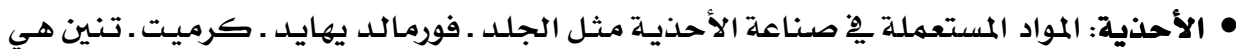
عوامل مثيرة للحساسية. • الفراء: مادة الجلد أو المواد المستعملة يِّ دباغـة وتجهيز الفـراء مثل بـارافنلين دايـامـين جميعها

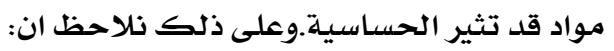

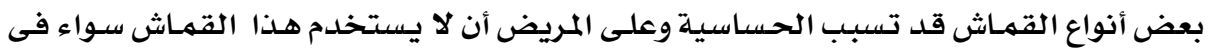

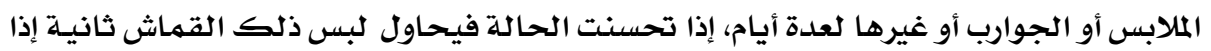

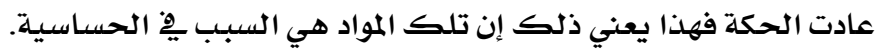
العوامل المسببة لحساسية القماش ا- الجلد الطري والحساس كمها هو الحال لدى الأطفال. r ب - ب السمنة المفرطة وزيادة الوزن.

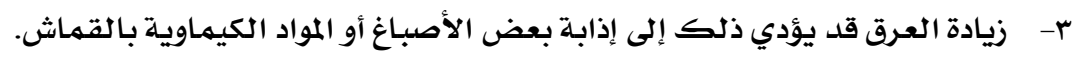

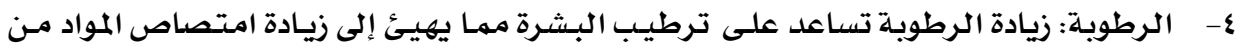
على سطح الجلد.

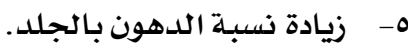

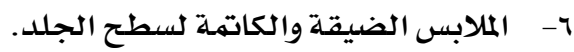

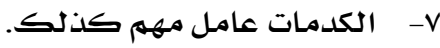

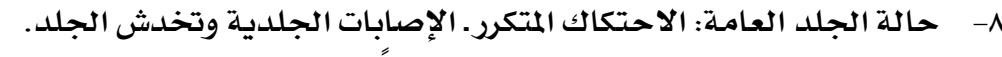

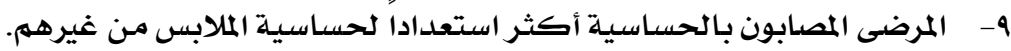

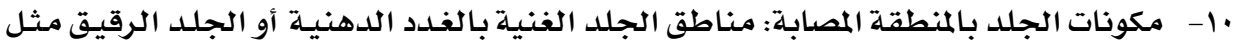

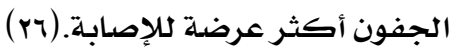
أعراض حساسية الملابس حساسية الملابس هي من النوع الذي يحلدث متأخرا نتيجة مـلامسة المادة المسببـة للحسساسية

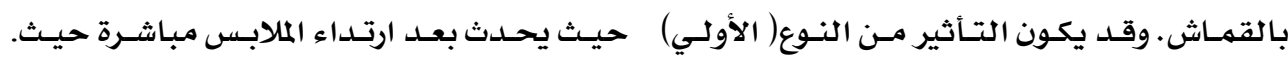


تبدأ الأعراض بحكة واحمرار بجلد المنطقة المعرضة للملبس و قد تكون الأعراض أثد بين ذوي البشرة

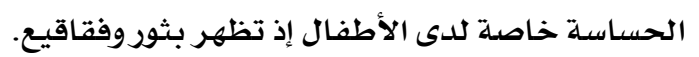

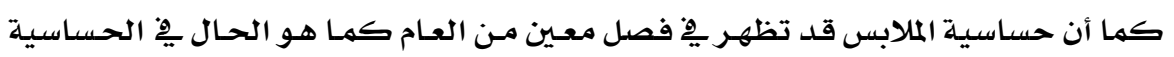

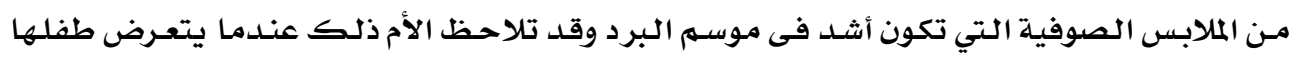
للهملابس الصوفية أو الأغطية الثقيلة.

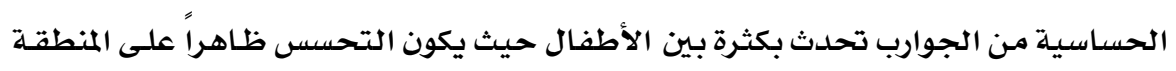

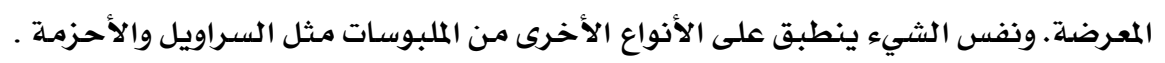
توجيهات هامه

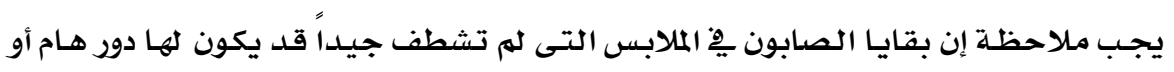

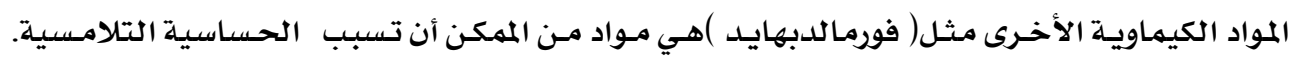

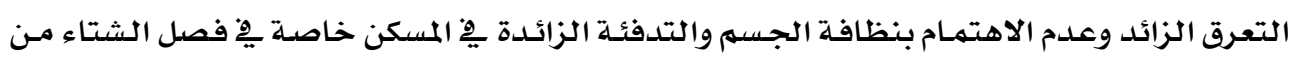
العوامل الهامـة كذلك للتهيئة للحساسية.

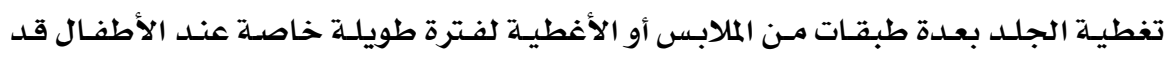
يؤدي التحسس الجلد. الرطوبة الزائدة والاحتكاك هي عوامل هامة كذلك.

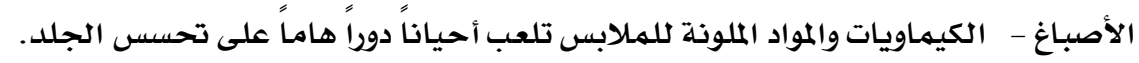

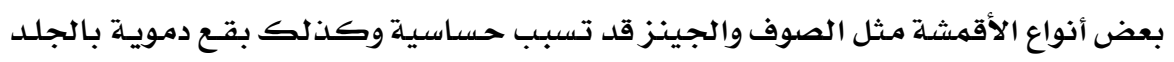

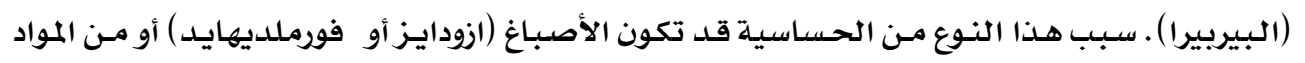

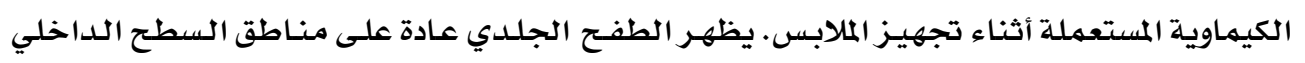

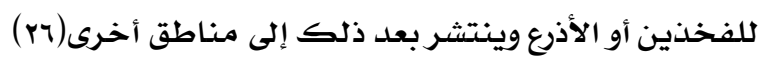

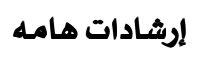
مثلما يطبق يِّ الأنواع الأخرى من أكزيما التماس.

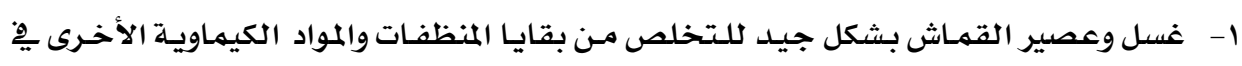

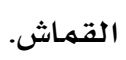

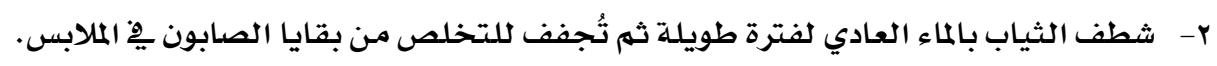

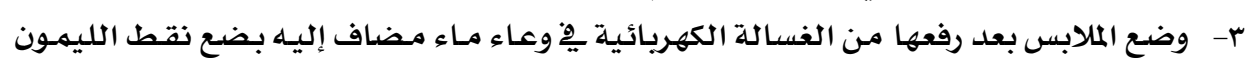

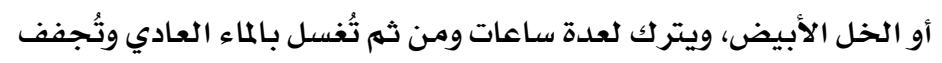




\section{ثالثا: الملابس الذكية للرعاية صصية أفضل}

مفهوم وأداء المنسوجات الذكية

يمكن تعريف المواد الذكية بأنها المواد التي تستجيب بكفاءة عاليـة لأي تغييرات مهمها بلغت

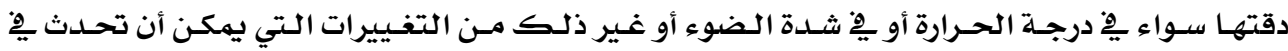

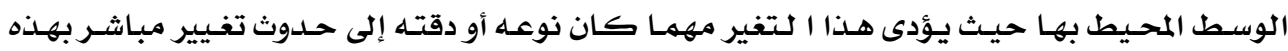

الألياف وبصوره ملحوظة.

وقد اكتسبت هـذه المواد صفة الذذكاء نظـرا لأنـة يمكنها أن تشعر بـالظروف المحيطلة بها

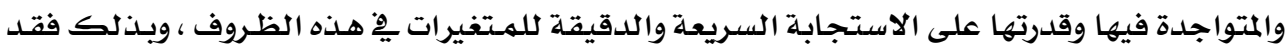
اكتسبت هذه المواد صفات لا تتوافر ِِِ مواد ومنسوجات أخرى كمها انه يمكنها استعادة حالتها الأولى

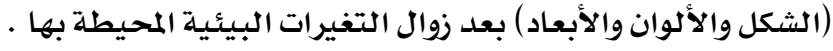

ومهم هنـا يتضـح أن المنسوجـات الذكيـة تمثل الجيل القـادم مـن الألياف والأقمشـة والمنتجـات

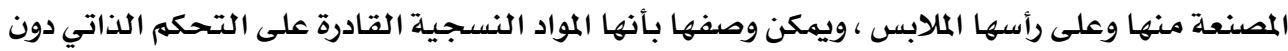

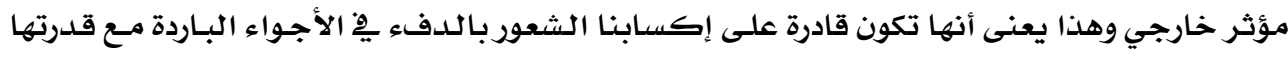

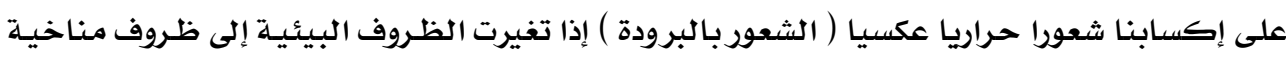
حارة دون حاجة منا إلى تغيرها أو إجراء أي تغيير يِ خاماتها أو تركيبـه النسجي. وانطلاقـا مـن هـذا المفهوم تصبـح المنسوجات الذكيـة قـادرة على أن تـوفر لنـا أسبـاب الراحسة والرعاية وإكسابنا الشعور بالبهجة والسرور أثناء أدائنـا المعتـاد لأنشطة الحيـاة اليوميـة،وقد أصبـحت

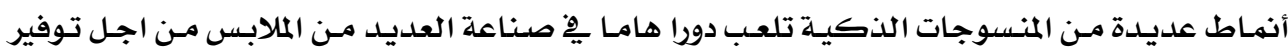

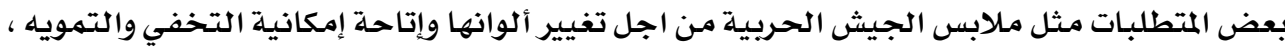

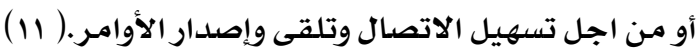
وفيما يلي سنعرض بعض أنواع من النماذج التي استخدمت فيها ألياف تتصف بالذكاء مـن اجل توفير ملابس تعطى رعاية صحية أفضل لمن يرتديها. طور العلماء الأوروبيون ملابس بجهاز حساس لمراقبة صحة الشخص الذي يرتديها

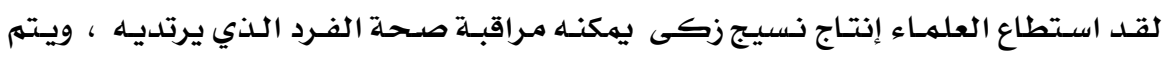

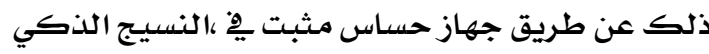

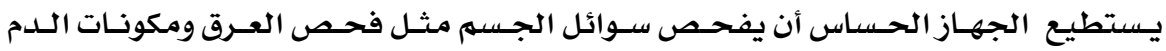

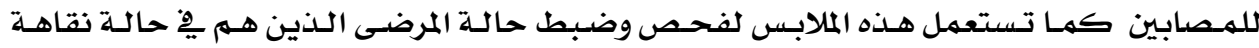
وأصحاب المرض المزمن.

ويـتم تطويرهـا حاليـا لتناسـب معظم الرياضسيـين لتستطيع قيـاس كميـة العـرق وتركيـز 


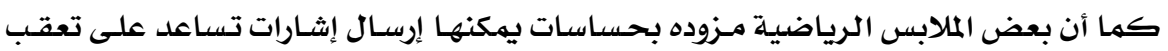

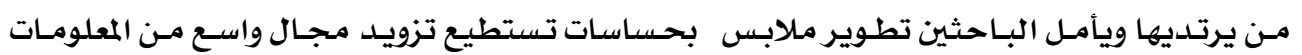

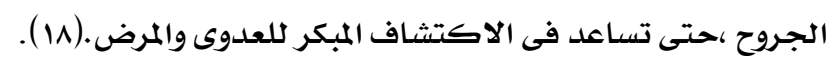
ملابس أطفال يتغير لونها عند ارتفاع حرارة الطفل

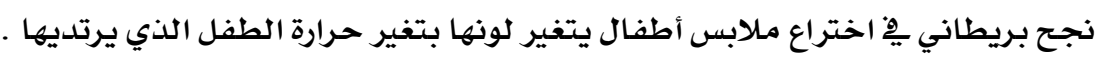

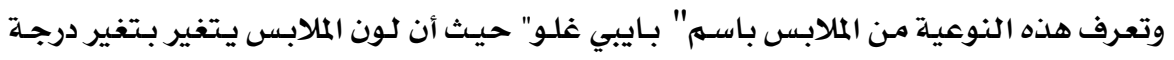

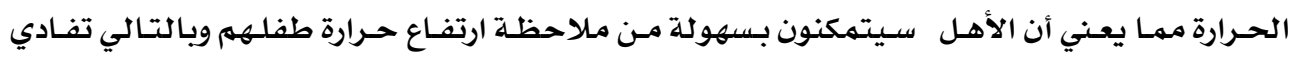

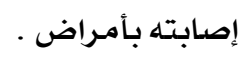

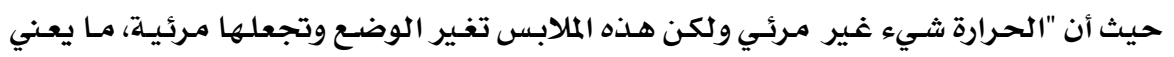

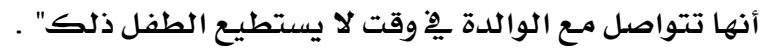

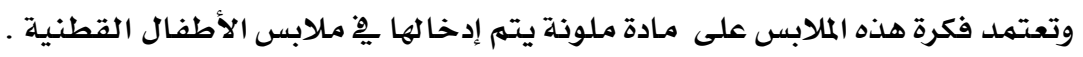

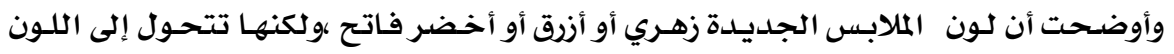

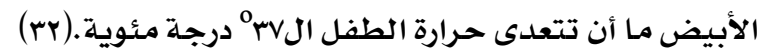

ملابس تَبريد للمَرضى مان تلتصدي

وكمثال آخر على المنتجات الطبية التي ابتكرها العلماء هي ( الملابس المبردة) لمرضى تصلب المبل

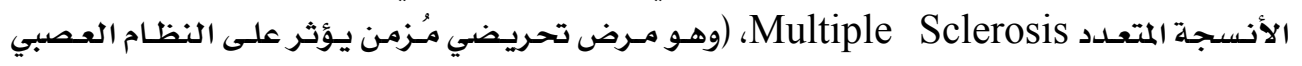

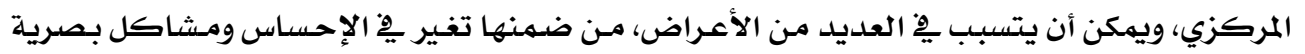

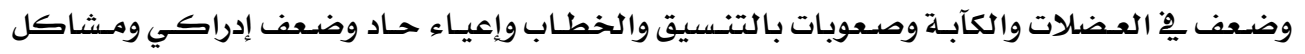

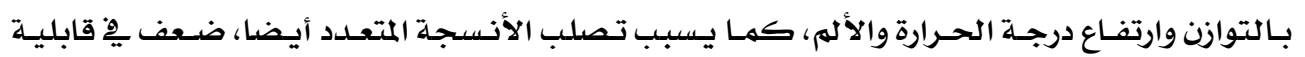

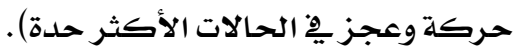

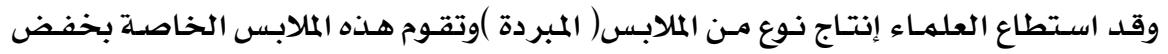

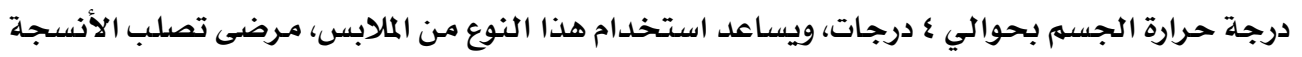

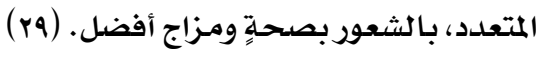

ملابس مكيفة الهواء

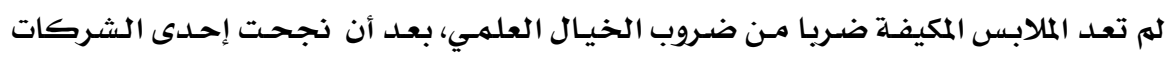

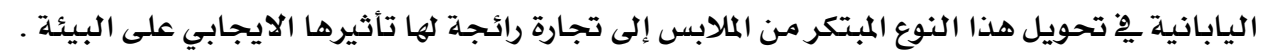

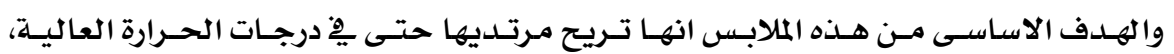

باستخدام واحد على خمسين من طاقة مكيف هواء صغير الحجمه .

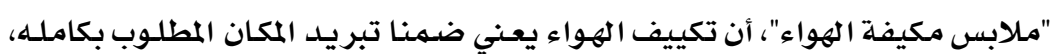

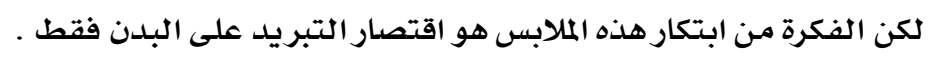




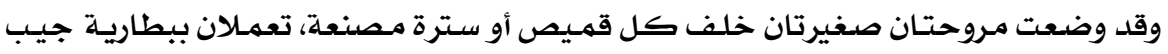

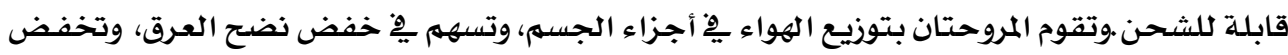

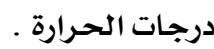

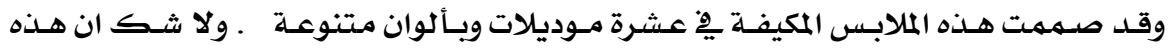

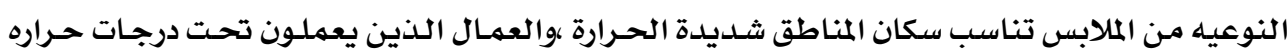
عاليه مثل عمال مصانع الحديد والصلب، وعمال الأفران.

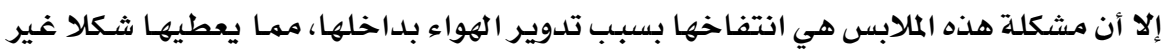

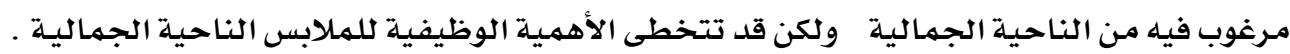

(

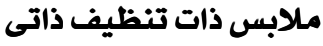

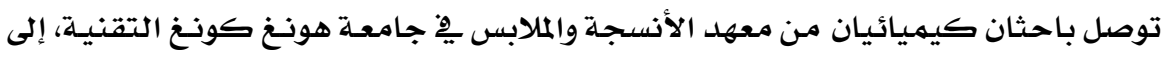

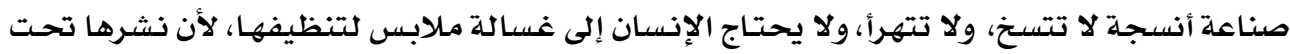
أشعة الشمس يكفي لتنظيفها.

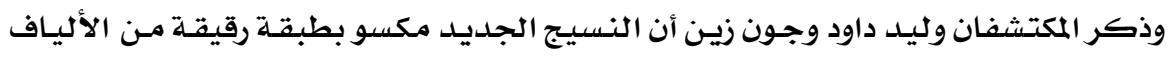

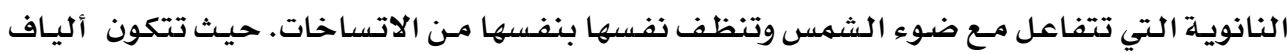

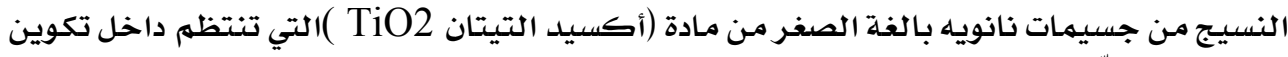

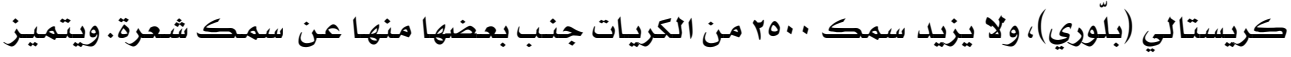

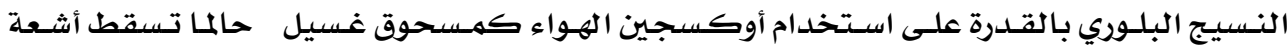

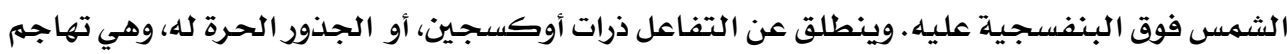

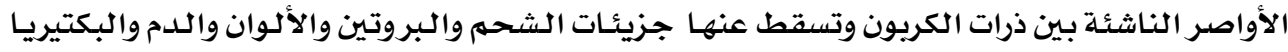

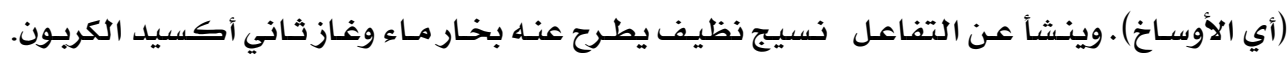

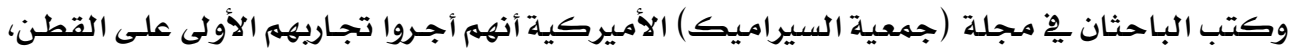

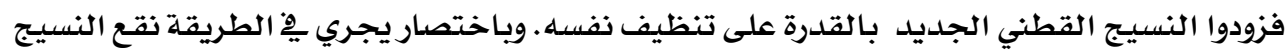

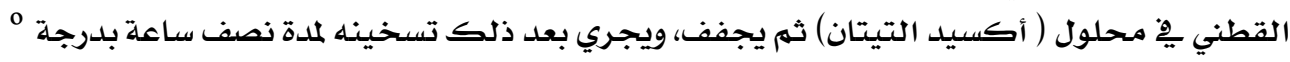

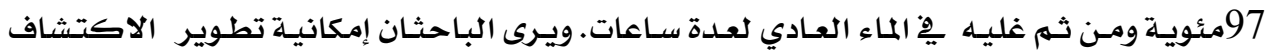

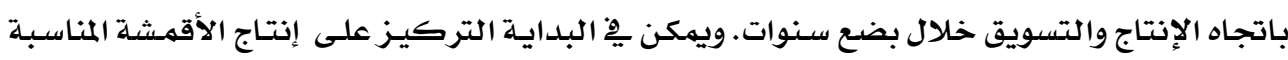

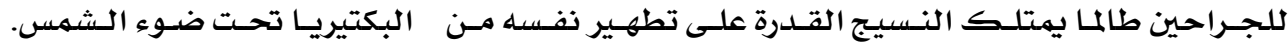

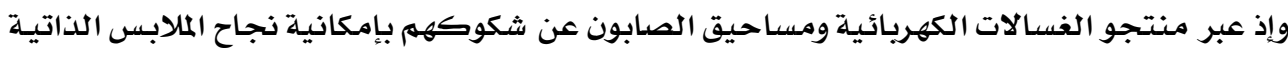

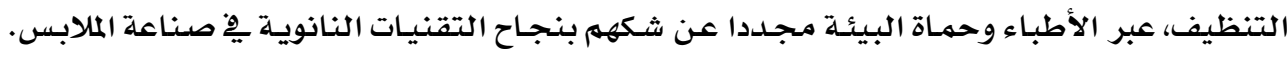

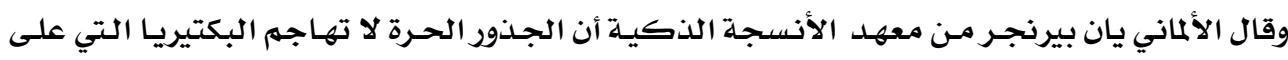

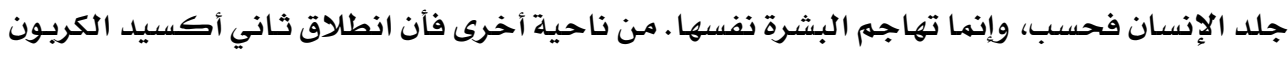

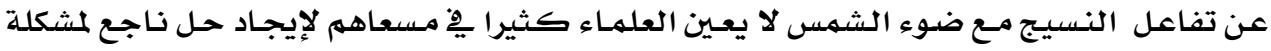




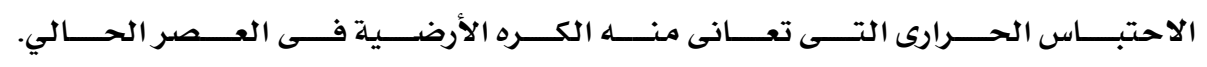

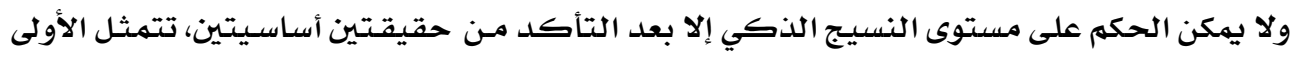

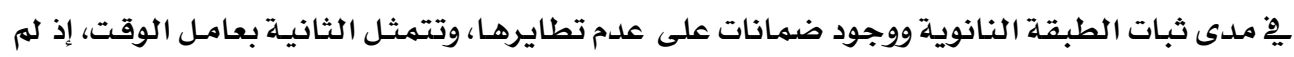

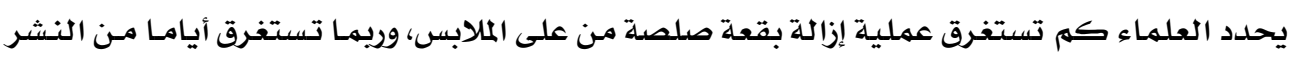

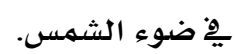

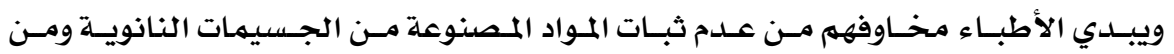

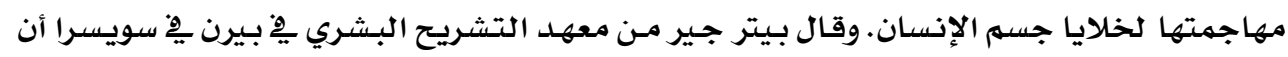

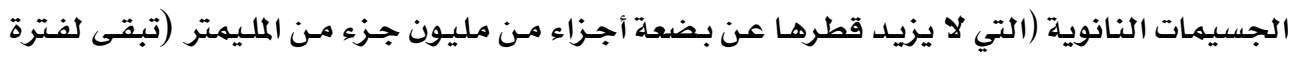

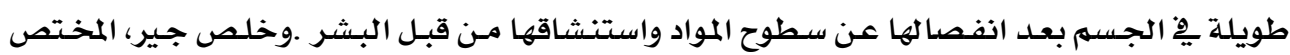

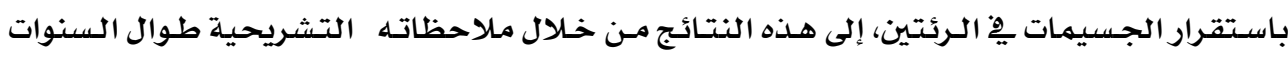

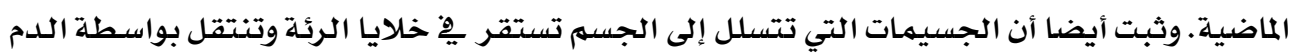
لتستقر يِّ أجزاء حيوية أخرى من جسمى الإنسان.

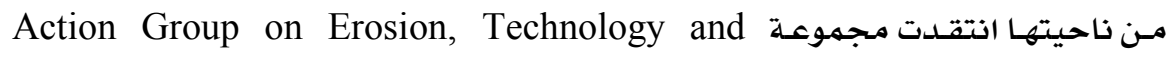
Concentration

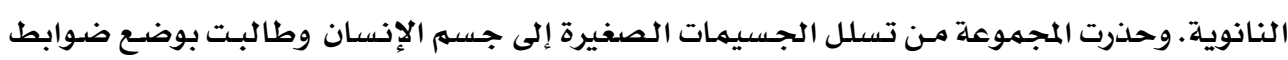

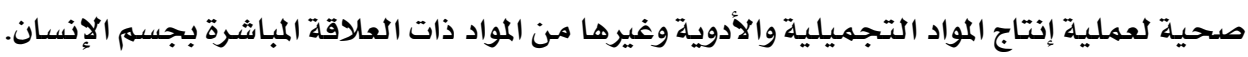

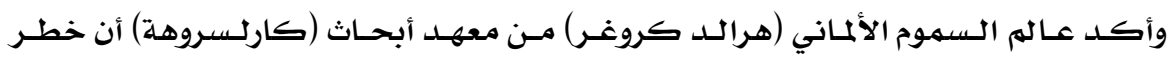

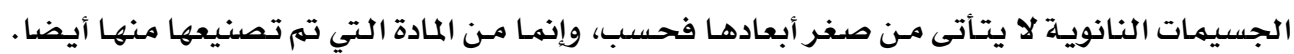

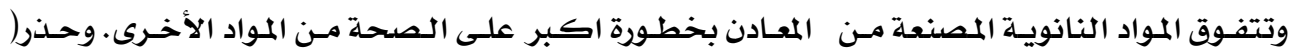

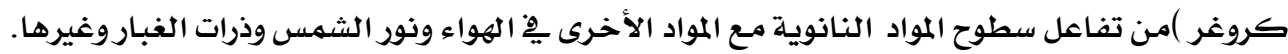

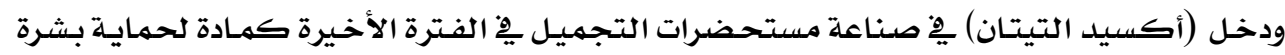

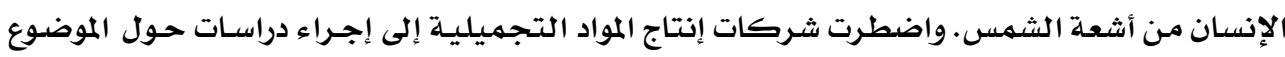

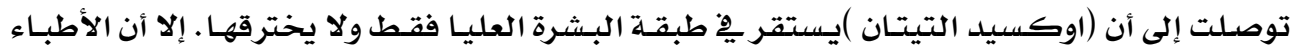
وحماة البيئة بقوا على شكهم من سلامة وضع (أكسيد التيتان )على جلودهر التهم.

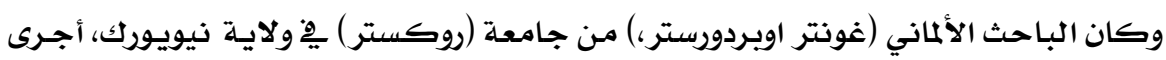

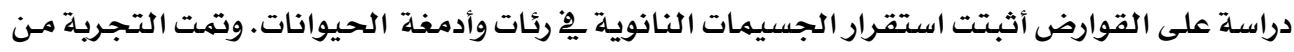

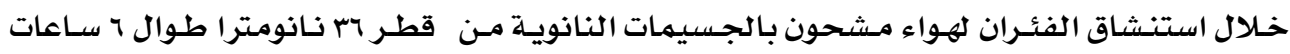




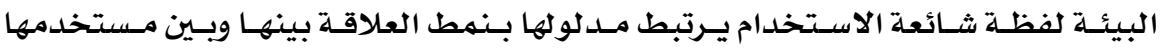

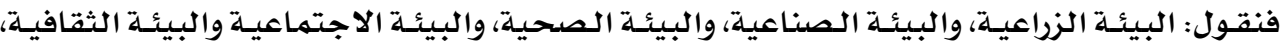

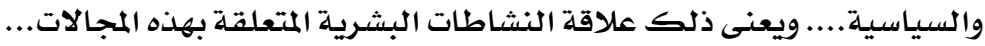

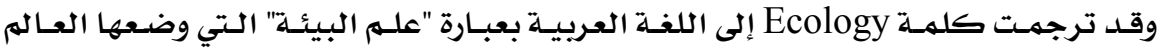

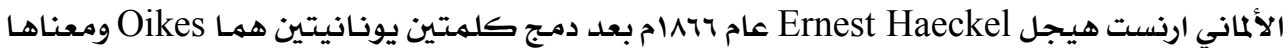

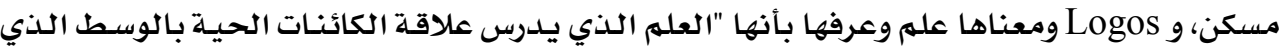

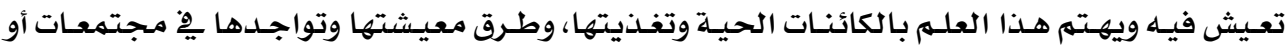

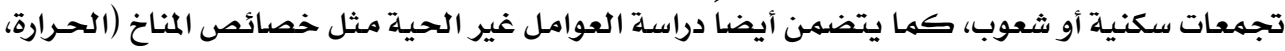

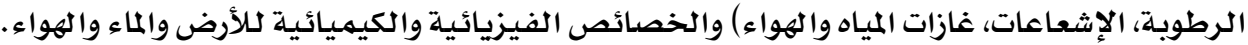

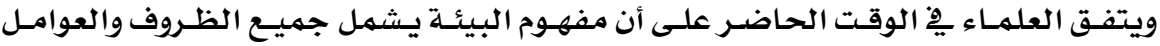

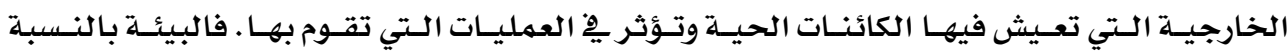

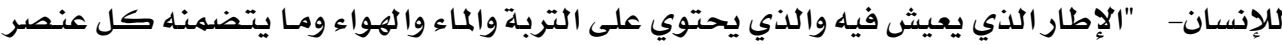

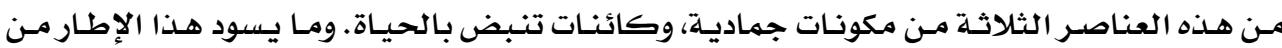
مظاهر شتى من طقس ومناخ ورياح وأمطار وجاذبية و مغناطيسية...الخ ومن علاقات متبـادلـة بـين هـذها.

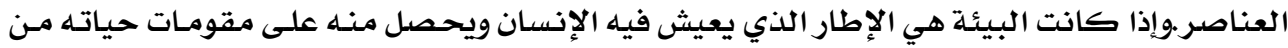

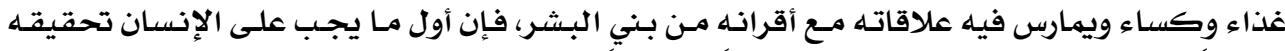

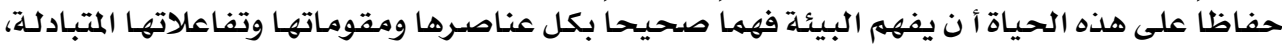

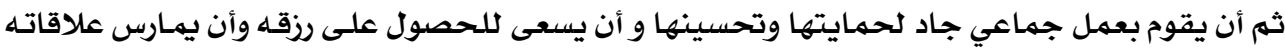

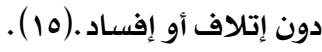

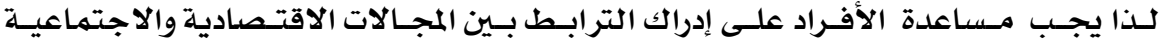

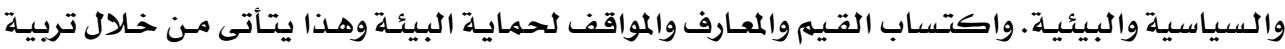

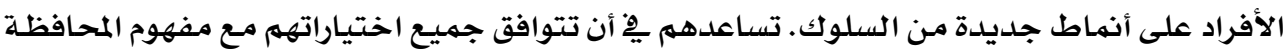

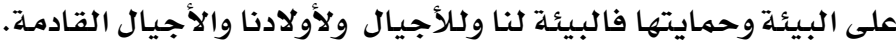

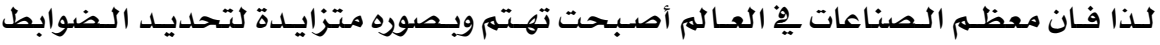

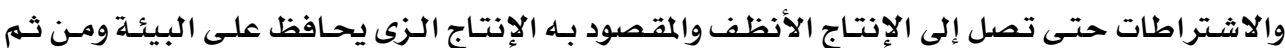
ألمحافظه على حياة البشر.

وكانت يف مقدمـة هـذه الصناعات صسناعة الملابس والمنسسوجات بصفتها صـناعه حيويـة لا

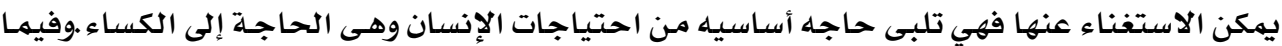

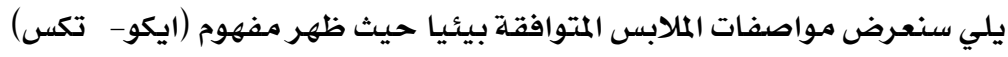




\section{OEKO - TEX standard مواصفات الايكو- تكس}

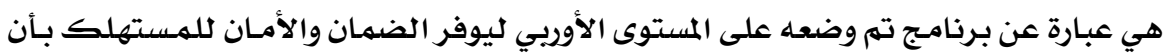

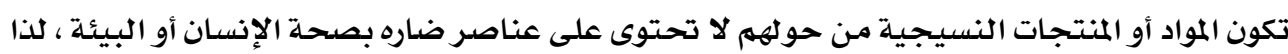

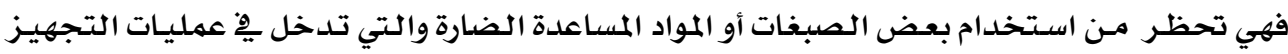

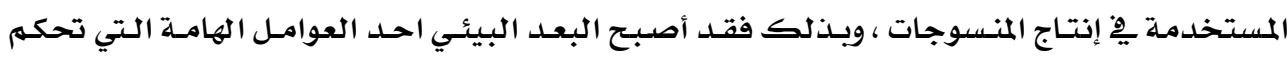
دخول السلع النسيجية من عدمها إلى المستهلك وليس ذوات المقات المستهلك فقط.

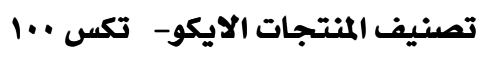

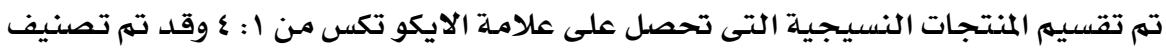

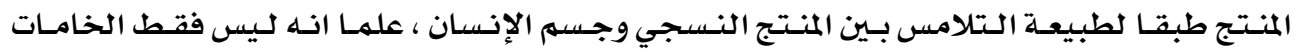

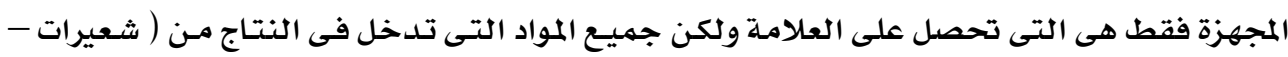

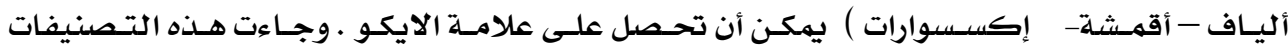
كالتالي:- اليساف

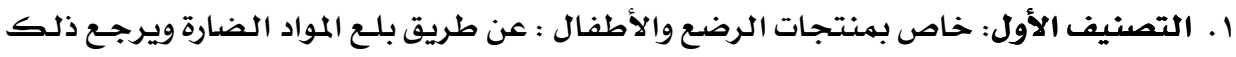

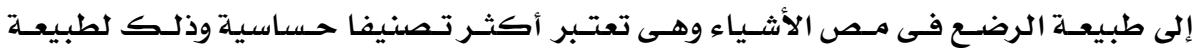

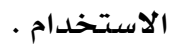

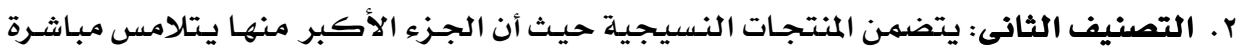

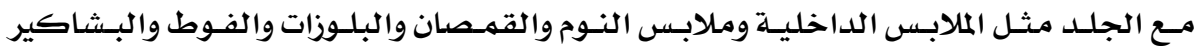

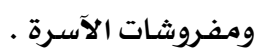
r. التصنيف الثالث : ويشمل المنتجات النسيجيه التي لا تتلامس مـع الجلد مباشرة كالملابس

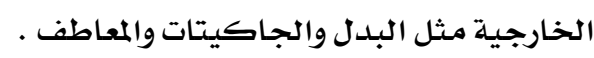

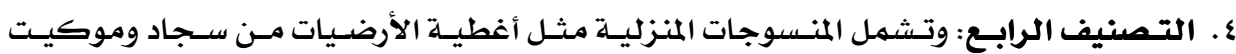

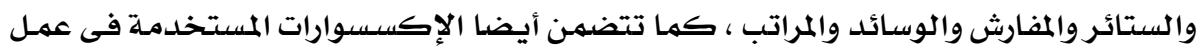

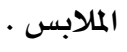

\section{OEKO TEX standard r.. مواصفات الايكو - تكس}

وهى تشتمل على طرق الاختبار الخاصة بالمواصفات الصحية والبيئية للمنتجات النسيجية

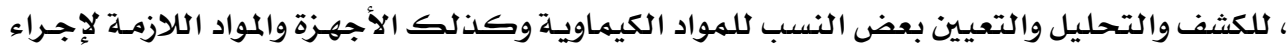

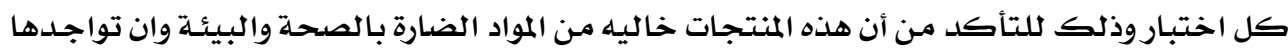

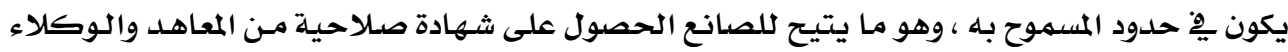

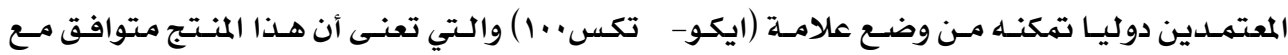

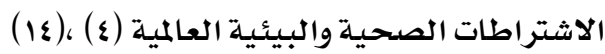
وفى حالة تجاوز نتائج أي من الاختبارات حدود السماح المقر ره فان إجـراء بـاقي الاختبـارات يتوقف تلقائيا . وفيما يلي عرض مختصر لهذنه الاختبارات: 


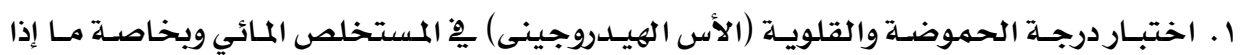

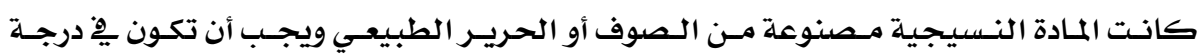

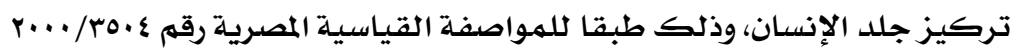

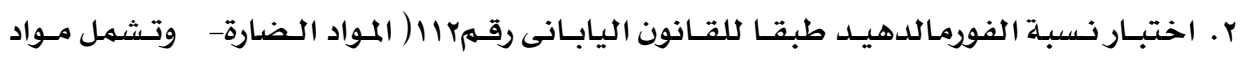

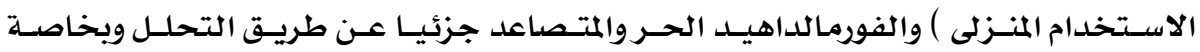

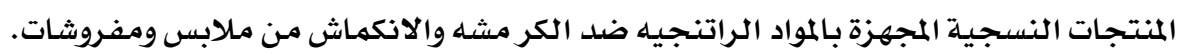

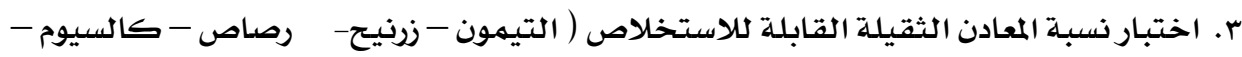

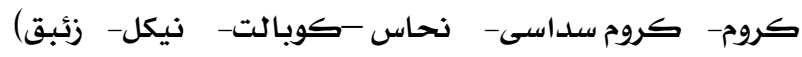
واقل تلك المعـادن خطورة هو النحساس فهسموح بنسبـة ـه (ج ف م) فِ حسين أن أخطرهـا الزئبقق

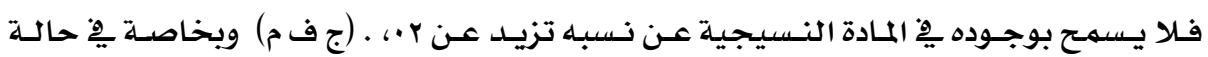
القطن الخام ويجب أن يراعى تضائل النسب المسموح بها من المعادن يْ حالة الملابس والمفروشات الخاصة بالأطفال.

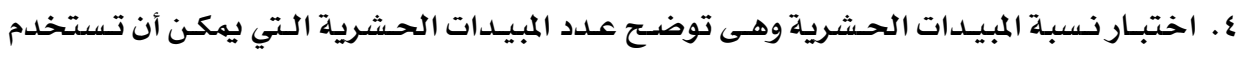

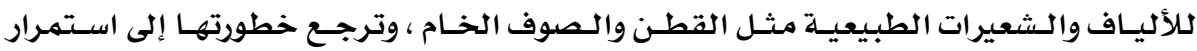
تواجدها لفترات طويلة بعد الاستخدام.

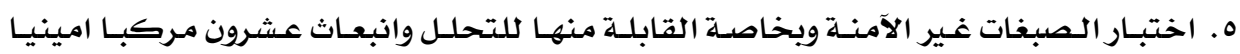

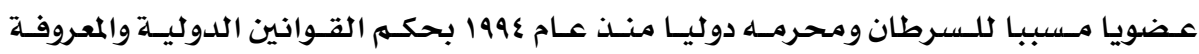

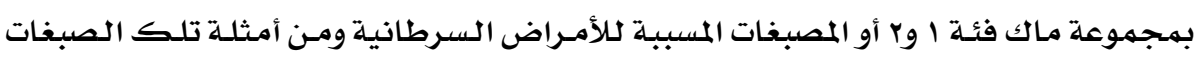

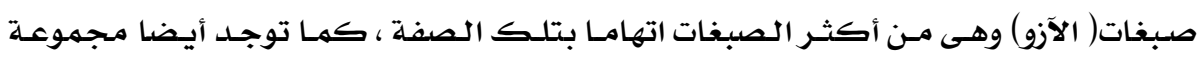

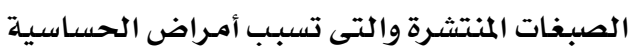

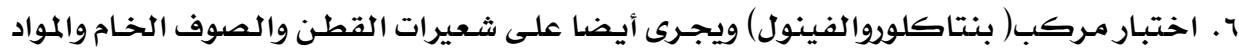

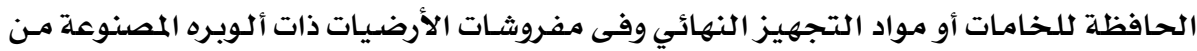
الصوف. V. اختبـار المواد الحاملـة لمركبـات الكلور العضوية والتتي تستخدم كمـاده مسـاعد على الصباغة وخاصة عند صباغة البولي استر بالصبغات المبات المنتشرة المبرة

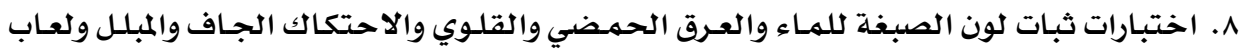

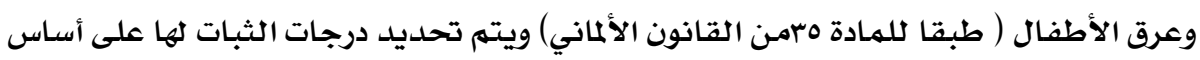

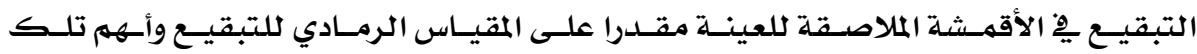

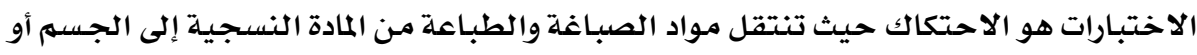
أفواه الأطفال. 9. تقدير انبعاث المواد الطيارة وهى تنبعث مـن المفروثات الخاصدة بأغطية الأرضيات مثل السجاد

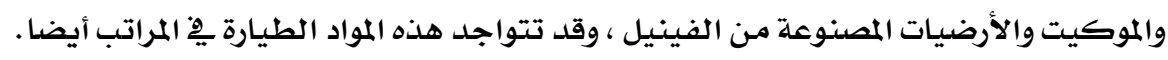




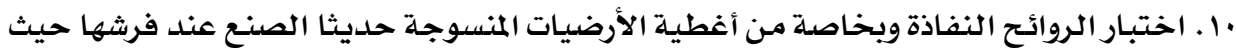

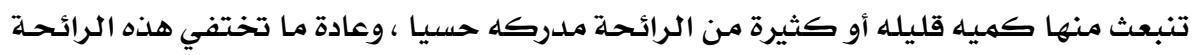

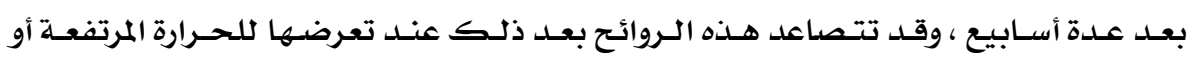

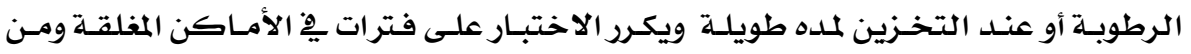

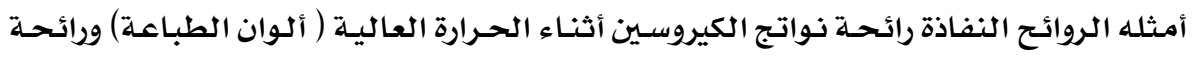

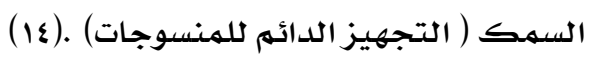

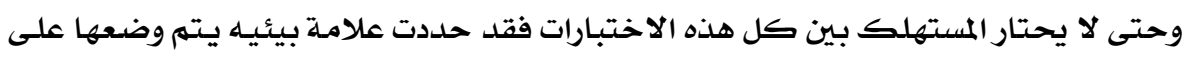

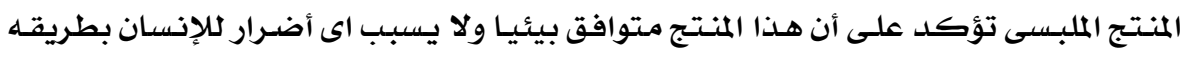
مباشره أو للبيئة بصفه عامه والتي بدورها تؤثر على الإنسان.

العلامة البيئية

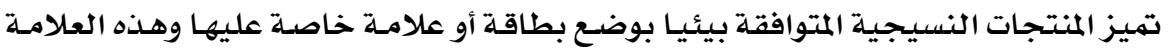

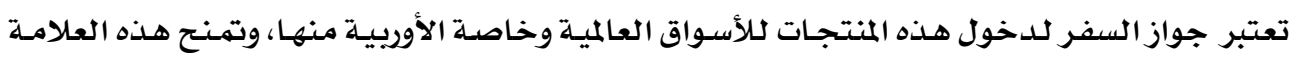

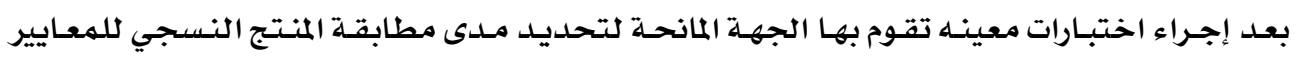

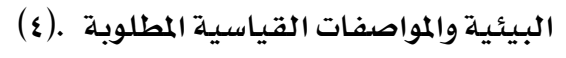

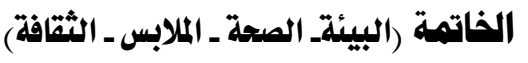

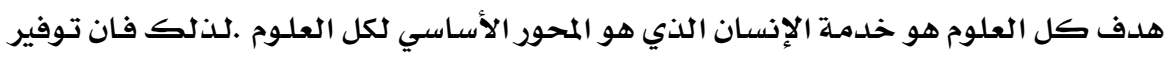

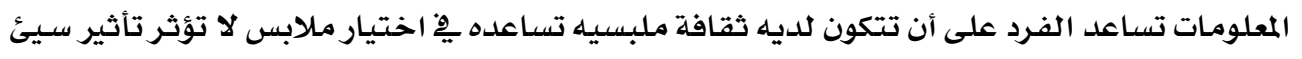

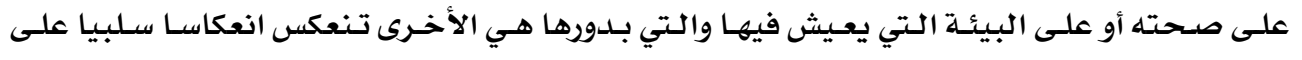
صحته.

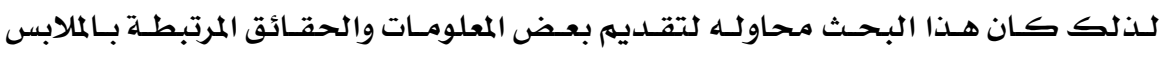

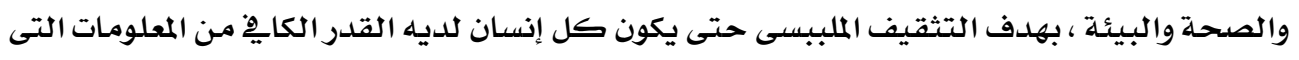

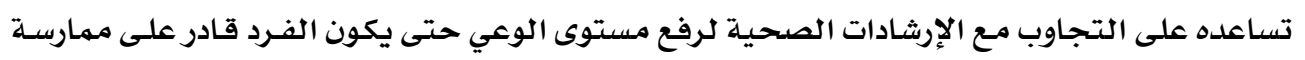

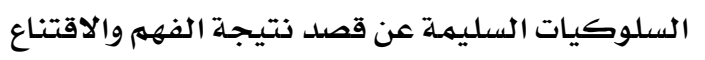
وبذلك يكون السلوك السليم عادة تمارس بلا شعور أو تفكير. 


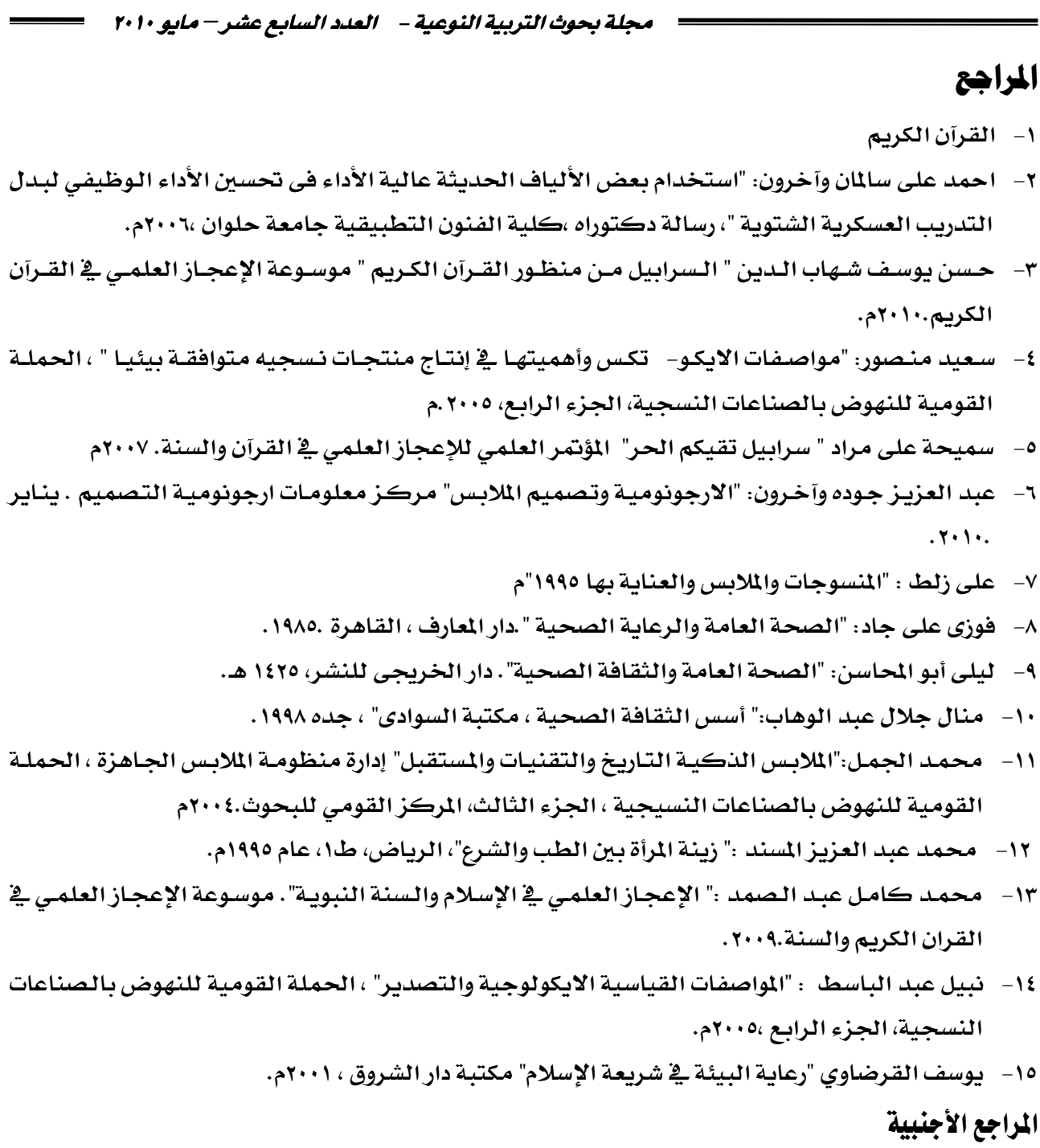

16-Cerbini, Stefano " Protective clothing against biological agents" United States Patent .Free Patents Online.com .2009

17-Chetelat, Catherine ,Chetelat, Michael "Assembled anti-creep waist-clothing stay device and method of reinforcing crotch-adjacent inner-seam area" United States Patent .FreePatentsOnline.com2009

18-Eberle, W., Homberger, M., Menzer, D., "Clothing Technology", 2nd edition, Lehmittel-Verlag Europa, Berlin 
19-El-hadidy, a. and el-bakry, m.: (2008) subjective evaluation of garment, 5th international conference, NRC, fex, devission, dokki, cario

20-Iwasaki, Hirohumi "Simplified warm-keeping body and warm-keeping clothFreePatentsOnline.com" 2009

21-Saudi Research \& Publishing Company (SRPC) 2009

22-W. D. Schindler and P. J. Hauser" Chemical Finishing of Textiles" Culinary and Hospitality Industry Publications Services2004 .

23-http://www.alriyadh-np.com

24- http//www.TKNET.net/vb/t213-ht.

25- http//:www.saudiinfocus.com 30-5-2005

26- http//: www.vitiligoarab.net

27 - http/ General Medicine Forum . com

28- http//www.albwaba.com.2007.

29- http//www.tabeb.com.2009.

30 -http//www.3ar00b.com.

31 -http//www.arabtex.com.

32-oloom@islamonline.net.

33- www.WHO.com. 